\title{
Diagnosis of Congenital Anomalies during Routine Fetal Surveillance
}

\author{
${ }^{1}$ Selami Sylejmani, ${ }^{2}$ B ajram Syla, ${ }^{3}$ Sebahate Shala
}

\begin{abstract}
Background: Birth defects are common in human development. Approximately $3 \%$ of newborns have a recognizable major anomaly, and at least $5 \%$ will ultimately be diagnosed with a congenital defect. Because of improvements in other areas of prenatal care, birth defects are the single most common cause of perinatal mortality in developed countries, accounting 20 to $25 \%$ of perinatal deaths. Now, many genetic and other disorders can be diagnosed early in pregnancy. S creening examinations during pregnancy are an essential part of prenatal care. A mong the various screening tests that are now offered to pregnant women, ultrasound (US) has the broadest diagnostic spectrum. There is no modality that can detect as many abnormalities during pregnancy as US. A priority goal in screening is the early detection of major fetal anomalies, which are defined as malformations that affect fetal viability and/or quality of life. During the past 10 years, some multicentric studies in Europe and USA show the successfulness of US diagnostics in detecting congenital abnormalities, even in women with low-risk pregnancy.
\end{abstract}

Definition of fetal anomalies: Any deviation from the normal range during morphogenesis, constitutes an anomaly. Major anomalies are malformations that affect viability and/or the quality of life and require intervention, and minor anomalies are malformations that are definitely present, but are minimal and usually have no functional significance (e.g. ear tags). Incidence data on major congenital anomalies vary considerably, depending on the type of detecting system used. The passive detection system reports 2 to $3 \%$ of newborns, meanwhile the active detection system, in which newborns are systematically examined by trained obstetricians, reports the incidence of congenital defects in $7.3 \%$ of all newborns.

Etiology: About $20 \%$ of anomalies in live-born infants are based on a defective gene, $10 \%$ are due to chromosomal abnormalities and $10 \%$ are mainly due to exogenous injury to the conceptus. Some $60 \%$ of all congenital anomalies are indeterminate or multifactorial causes (hereditary factors and environmental influences). Ultrasound can detect about $74 \%$ of major birth

\footnotetext{
${ }^{1} \mathrm{P}$ rivate $\mathrm{P}$ ractitioner, ${ }^{2} \mathrm{Head},{ }^{3}$ Senior Registrar

${ }^{1}$ Department of Obstetrics and Gynecology, Private Office 'Klinika Ginekos', P rizren, Kosovo

${ }^{2}$ Department of Mother and Child, Regional Hospital, Ferizaj Kosovo

${ }^{3}$ Department of Obstetrics and Gynecology, University Clinical Center, Prishtina, Kosovo
}

Corresponding Author: Selami Sylejmani, Private Practitioner 'Klinika Ginekos', Prizren, Kosovo, Phone: 37744502625, e-mail: selami.sylejmani@gmail.com defects and possibly a higher number, when conducted by a well-trained specialist. We have demonstrated in this paper some fetal anomalies found by US during our practice in Kosovo. There are some different anomalies of almost all systems of the organs of the fetal body, some of them more frequent and some very rare anomalies.

Conclusion: Ultrasound diagnostic is a very useful method for evaluating the fetal health, fetal anomalies, anomalies of placenta and amniotic fluid as well as umbilical cord.

Keywords: Congenital anomalies, Fetal surveillance, Ultrasound.

How to cite this article: Sylejmani S, Syla B, Shala S. Diagnosis of Congenital Anomalies during Routine Fetal Surveillance. Donald School J Ultrasound Obstet Gynecol 2015; 9(2):159-174.

\section{Source of support: Nil}

Conflict of interest: None

\section{INTRODUCTION}

\section{Background}

Birth defects are common in human development. Approximately $3 \%$ of newborns have a recognizable major anomaly, and at least $5 \%$ will ultimately be diagnosed with a congenital defect. Because of improvements in other areas of prenatal care, birth defects are the single most common cause of perinatal mortality in developed countries, accounting 20 to $25 \%$ of perinatal deaths. Now, many genetic and other disorders can be diagnosed early in pregnancy. Screening examinations during pregnancy are an essential part of prenatal care. Among the various screening tests that are now offered to pregnant women, ultrasound (US) has the broadest diagnostic spectrum. There is no modality that can detect as many abnormalities during pregnancy as US. A priority goal in screening is the early detection of major fetal anomalies, which are defined as malformations that affect fetal viability and/or quality of life. ${ }^{1}$ During the past 10 years, some multicentric studies in Europe and USA show the successfulness of US diagnostics in detecting congenital abnormalities, even in women with low-risk pregnancy.

The passive detection system report 2 to $3 \%$ of newborns, ${ }^{2,3}$ meanwhile the active detection system, in which newborns are systematically examined by trained obstetricians, report of the incidence of congenital defects in 7.3\% of all newborns. ${ }^{4,5}$ About $20 \%$ of anomalies in live-born infants are based on a defective gene, $10 \%$ are due to 
chromosomal abnormalities and $10 \%$ are mainly due to exogenous injury to the conceptus. Some $60 \%$ of all congenital anomalies are indeterminate or multifactorial causes (hereditary factors and environmental influences).

\section{Central Nervous System Anomalies}

Views of the brain and head are among the most important images the sonographer can obtain for exclusion of a wide variety of anomalies. Central nervous system (CNS) malformations are some of the most common yet devastating of all congenital abnormalities. The incidence of these malformations may be as high as one in 100 births. ${ }^{6}$ Additionally, congenital CNS abnormalities are associated with an increased rate of spontaneous abortion, adding to their rate of in utero occurrence when compared to birth rate statistics. ${ }^{7}$ Eventually, CNS malformations may be associated with a variety of genetic disorders and chromosomal abnormalities which may be important for genetic counseling of the patients. ${ }^{8}$

\section{Anencephalia-Acrania}

The calvaria can be readily identified from the late first trimester until term. Exencephaly is the predecessor of anencephaly. In exencephaly, the brain is exposed due to the complete absence of the calvarium, skin, and meninges. Anencephaly occurs later in the sequence, and in addition to the findings of exencephaly, the forebrain is also missing. Incidence of about 1 case per 1000 live births. ${ }^{9,10}$ Pathogenesis is divided in three phases: dysraphia, or failure of the neural groove to close in the rostral region between 18 and 20 postovulatory days; exencephaly, or exposure of a well-differentiated brain outside the skull during the embryonic period; disintegration of the exposed brain during the fetal period, resulting in anencephaly. ${ }^{11-13}$

The sonographic findings are absence of cranium beyond the area of the forehead with exposed brain tissue, absent cranium with prominent orbits and preservation of the base of the skull and facial features, echogenic amniotic fluid (Fig. 1). ${ }^{14}$ Association with chromosomal abnormality can be seen in about $2 \%$ of cases. Can be reliably diagnosed at the time of the first-trimester screen (nuchal translucency scan).

Cephaloceles are cranial defects, along bony sutures, in which there is a herniation of the brain or the meninges, or both. Cephaloceles can be occipital, parietal, or frontal; If the cephalocele sac contains brain tissue, it is termed an encephalocele; if only cerebrospinal fluid is present, it is termed a meningocele. Incidence ranges from 1 in 3500 to 1 in 5000 live births (Fig. 2). ${ }^{15}$ Occipital encephalocele is most common. ${ }^{15}$ Usually isolated, but in a small percentage of cases may be a part of a chromosomal or nonchromosomal syndrome.

\section{Hydrocephalus}

The lateral ventricles are complex anatomic structures that lie deep within the cerebral hemispheres. Severe lateral ventriculomegaly can result from different pathological entities. Fetuses with this finding usually have other neural and extraneural malformations. Even those with presumably isolated ventricular dilatation were found in the majority of cases to have complex abnormalities
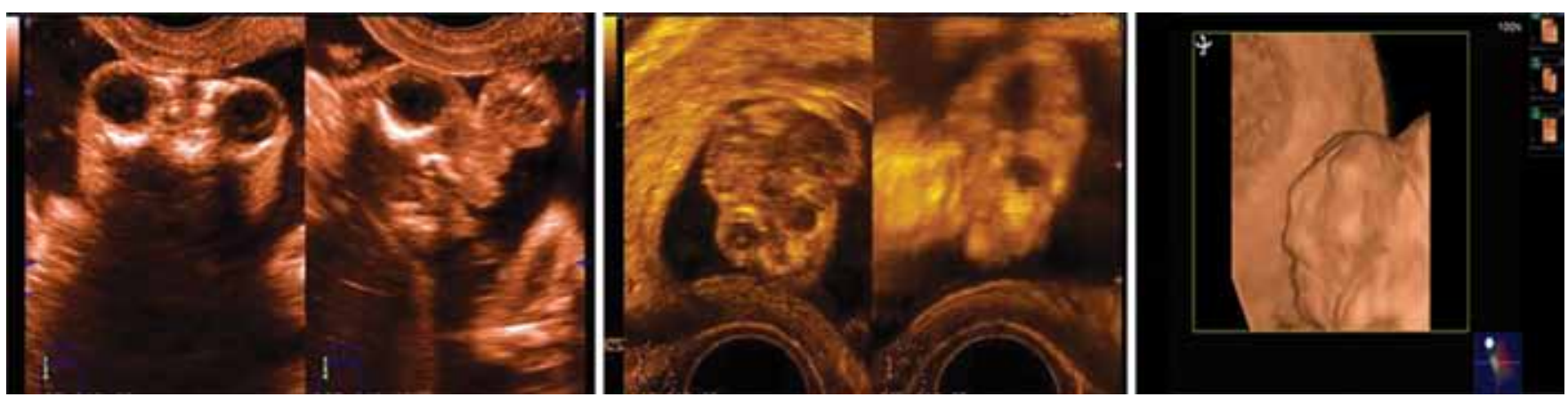

Fig. 1: Anencephalus
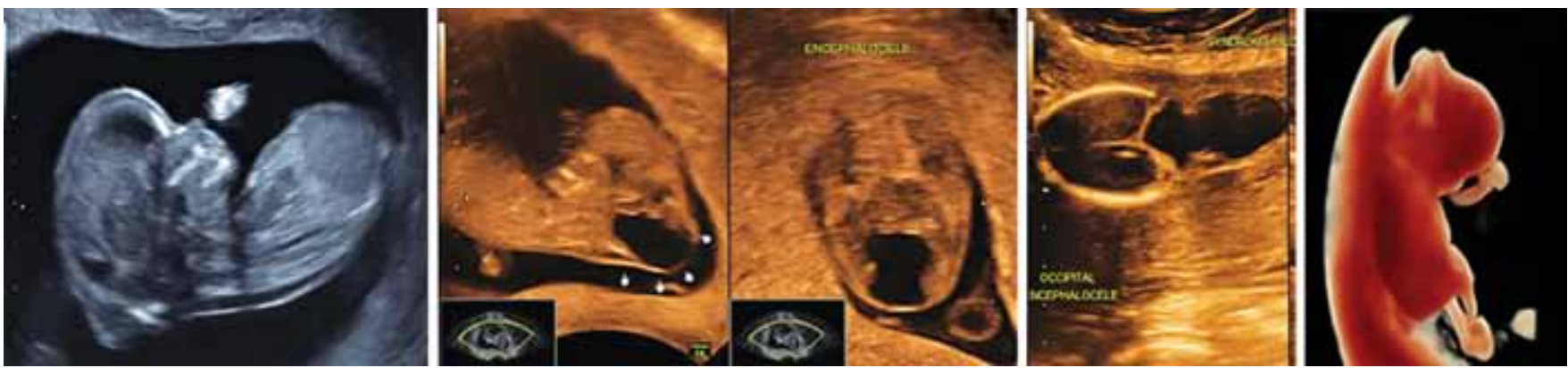

Fig. 2: Encephalocele 

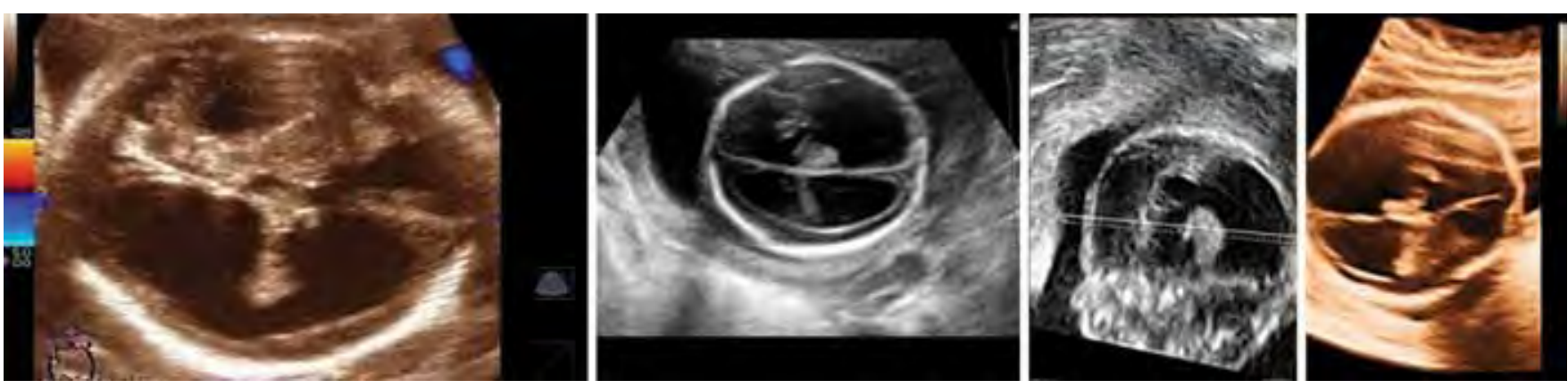

Fig. 3: Hydrocephalus

including. In a large series, only $10 \%$ of fetuses with severe ventricular dilatation were found not to have associated malformations. ${ }^{16}$ Only in a small proportion fetuses are found to have isolated obstructive hydrocephalus, either acqueductal stenosis or communicating hydrocephalus. In these cases, the degree of ventricular enlargement is variable. Knowledge about the pathogenesis of congenital ventriculomegaly is largely incomplete. Thinning of the cortex, macrocrania and symptoms of intracranial hypertension are frequently found (Fig. 3). Recurrence risk is about $4 \% .{ }^{17} \mathrm{X}$-linked hydrocephalus has a recurrence risk $50 \%$ of males.

\section{Holoprosencephalus}

Another entity involving ventricles is holoprosencephaly. It is a genetically and phenotypically heterogeneous disorder, involving the development of the forebrain and midface. Incidence is about 1 in $16000 .^{18}$ This condition is associated with high intrauterine fatality rate, and it is likely that the obstetric sonographers encounter it more frequently than expected from epidemiologic surveys at birth. The most valuable clue to the diagnoses is the demonstration of the single primitive ventricle ${ }^{19}$ and fused central thalami (Fig. 4). The facial anomalies, such as cyclopia, hypotelorism, anophtalmia, arhinia, proboscis (Fig. 4) and median cleft lip may be present. ${ }^{20}$

Hydranencephalus is a rare brain malformation that results from destructive process in which both cerebral hemispheres may be entirely or almost entirely absent with cerebrospinal fluid filling the space. The falx may be incomplete or absent. The head size, cerebellum and the brainstem are normal.

Incidence is rare about 1 to 2 per 10,000 births. The cause is ischemic stroke of both internal carotid arteries
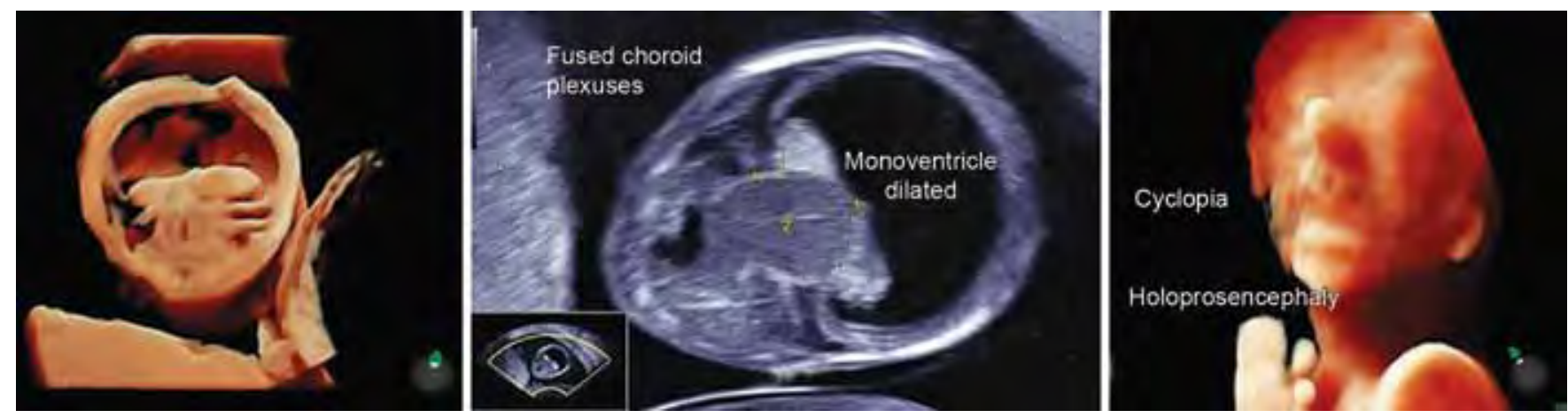

Fig. 4: Alobar holoprosencephaly associated with facial malformation-proboscis
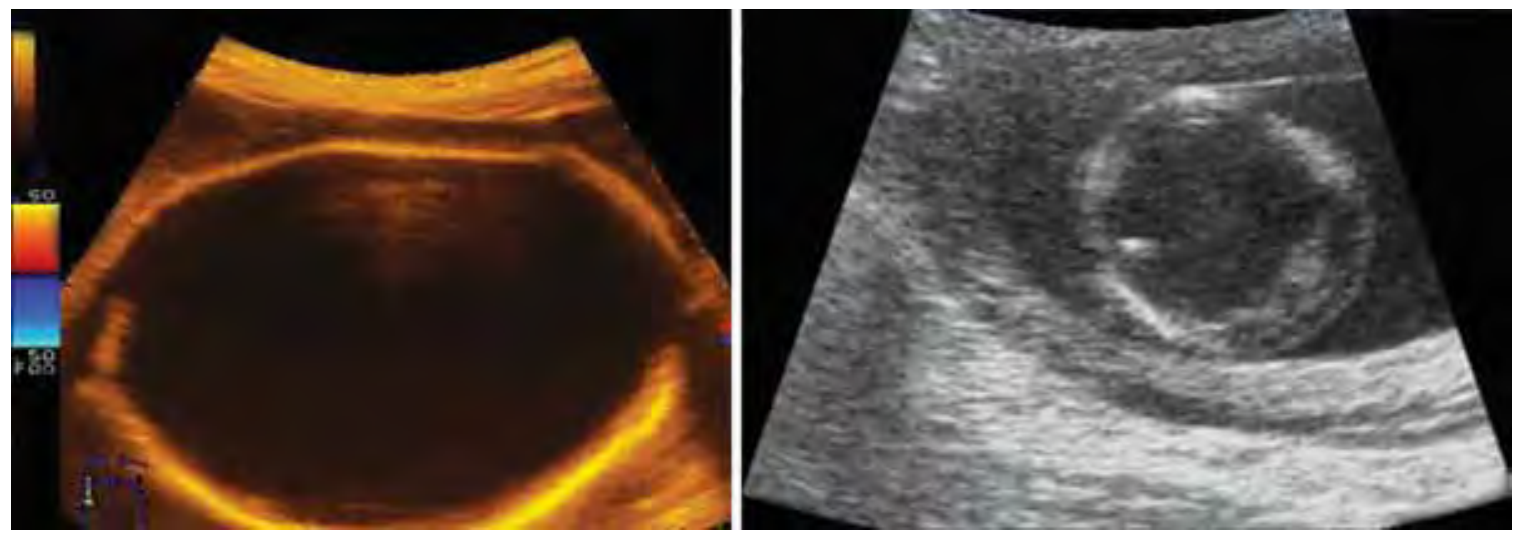

Fig. 5: Hydranencephalus 
occurring as early as the 11 th postmenstrual weeks. ${ }^{21}$ The areas affected by the infarct undergo tissue necrosis and resorption, leaving behind a cavity in the brain which is filled by a thin-walled fluid cyst (Fig. 5).

Arachnoidal cysts are the accumulation of cerebrospinal like-fluid between the cerebral meninges. Incidence is rare and they represent $1 \%$ of all intracranial masses of the newborn. ${ }^{22}$ They may be primary (congenital) or secondary (acquired). Arachnoid cysts have been found anywhere in the CNS including the spinal canal. Ultrasound examination of arachnoid cysts demonstrates a well-defined anechoic lesion with adjacent mass effect (Fig. 6). Usually are evident only in the third trimester.

\section{Differential Diagnosis}

Porencephaly, schizencephaly, unilateral ventriculomegaly, etc.

In many cases, they are asymptomatic but due to a compression can cause epilepsy, mild motor or sensory abnormalities or hydrocephalus.

\section{Dandy-Walker Complex}

The term is introduced to indicate the association of ventriculomegaly of variable degree, a large cisterna magna and a defect in the cerebellar vermis through which the cyst communicates with the fourth ventricle. By using axial CT scans these anomalies are categorized as follows:

Classic Dandy-Walker malformation: Enlarged posterior fossa, complete or partial agenesis of cerebellar vermis, elevated tentorium.

Dandy-Walker variant: Variable hypoplasia of the cerebellar vermis with or without enlargement of posterior fossa.

Megacisterna magna: Enlarged cisterna magna with integrity of cerebellar vermis and fourth ventricle.

Incidence of Dandy-Walker malformation is approximately 1 per 30,000 births and is found in 4 to $12 \%$ of all cases of infantile hydrocephalus. ${ }^{23}$

Diagnoses have been frequently during prenatal period ${ }^{23}$ even in the first trimester. ${ }^{24}$ Communication between an enlarged cisterna magna and fourth ventricle through a defect in the cerebellar vermis (Fig. 7) is a condition for diagnoses either malformation or variant of Dandy-Walker. Borderline to overt ventriculomegaly and other neural and extraneural malformations are frequently present with Dandy-Walker malformation.

Caution is encouraged during the early second trimester in making of diagnoses of partial vermian agenesis because the incompletely inferior cerebellar vermis may give the false impression of a vermian defect. ${ }^{25}$
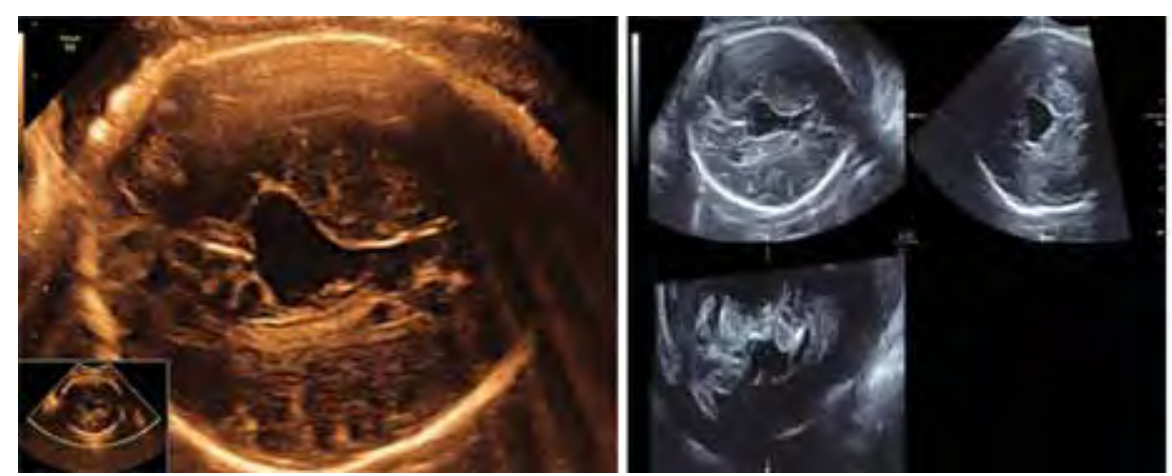

Fig. 6: Arachnoidal cysts
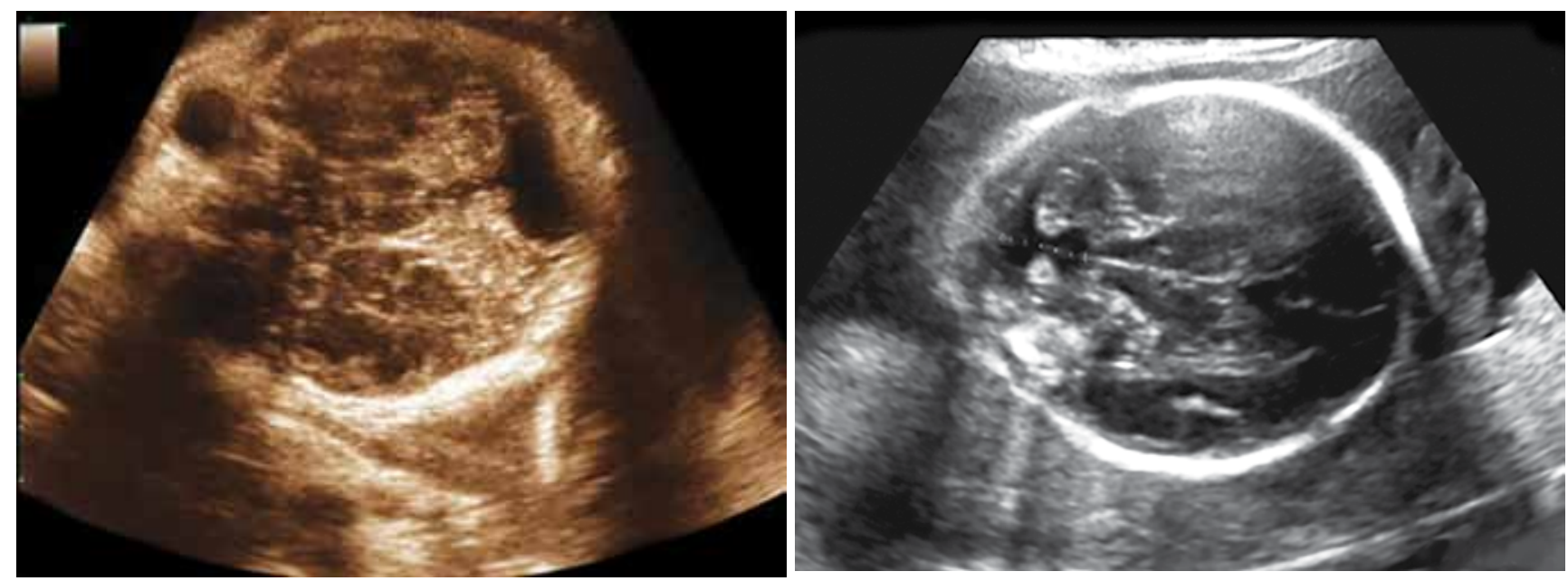

Fig. 7: Dandy-Walker malformation 


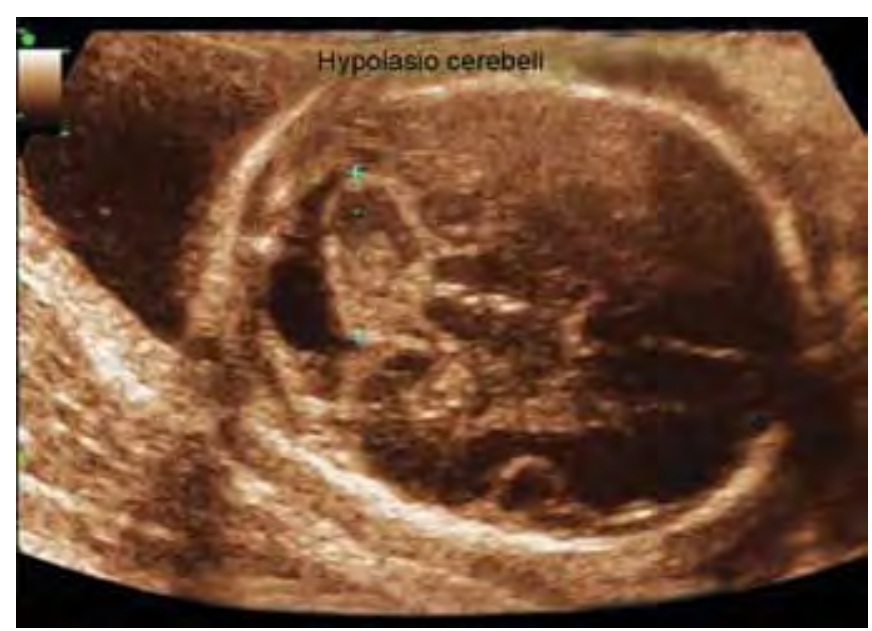

Fig. 8: Cerebellar hypoplasia

An enlarged cisterna magna typically measures greater than $10 \mathrm{~mm}$ in anteroposterior diameter. ${ }^{26}$ When an enlarged cisterna magna is the only finding, especially during the third trimester the overwhelming outcome is normal but it should stimulate a careful search for other anomalies. Cerebellar hypoplasia (Fig. 8) is a rare finding which can be isolated or as a part of different syndromes, such is, Walker-Warburg syndrome, Williams syndrome or ataxia telangiectasia.

\section{Neural Tube Defects (NTD)}

Spina bifida encompasses a broad spectrum of abnormalities. ${ }^{27}$ Lesions are commonly subdivided into ventral and dorsal defects. Ventral defects are extremely rare. Dorsal defects are by far the most common. They are subdivided into two types: open and closed spina bifida. Closed spina bifida represents approximately $15 \%$ of cases diagnosed at birth and is characterized by a defect covered by skin, usually in association with an area of hypertrichosis, pigmented or dimpled skin. In many cases, closed spina bifida is asymptomatic, although neurologic sequelae, such as lower extremities dysfunction and incontinence, of variable severity can be seen. Hydrocephalus is however usually absent. The presence of a fistula may result in neural infection.

Open spina bifida is the most frequent lesion diagnosed at birth, resulting in $85 \%$ of dorsal defects. The neural canal may be exposed, or the defect may be covered by a thin meningeal membrane (myelocele) (Fig. 9). More often, the lesion appears as a cystic tumor (spina bifida cystica). Neural tissue is part of the mass, and the name 'myelomeningocele' is used. The term 'myeloschisis' is sometimes used to refer to a condition in which the spinal cord is widely opened dorsally and is part of the wall of the myelomeningocele. The vertebrae are lacking the dorsal arches, and the pedicles are typically spread apart. ${ }^{27}$

\section{Associated Anomalies}

The two main categories of anomalies associated with spina bifida are other central nervous system defects and foot deformities. In almost all cases of open spina bifida, a typical abnormality of the posterior fossa is found. The lesion is referred to as Chiari type II malformation, ${ }^{27}$ and it is characterized by a herniation of the cerebellar vermis through the foramen magnum. The fourth ventricle is displaced downward inside the neural canal. The posterior fossa is shallow and the tentorium is displaced downward. Displacement and kinking of the medulla are also observed. Arnold-Chiari malformation is almost invariably associated with obstructive hydrocephalus. The genesis of hydrocephalus seems to be related to the low position of the exit foramen of the fourth ventricle which drains the cerebrospinal fluid inside the spinal canal. Re-entry of the fluid to the intracranial cavity is then blocked by the cerebellum that obstructs the foramen magnum. In many cases, deformities of the aqueduct
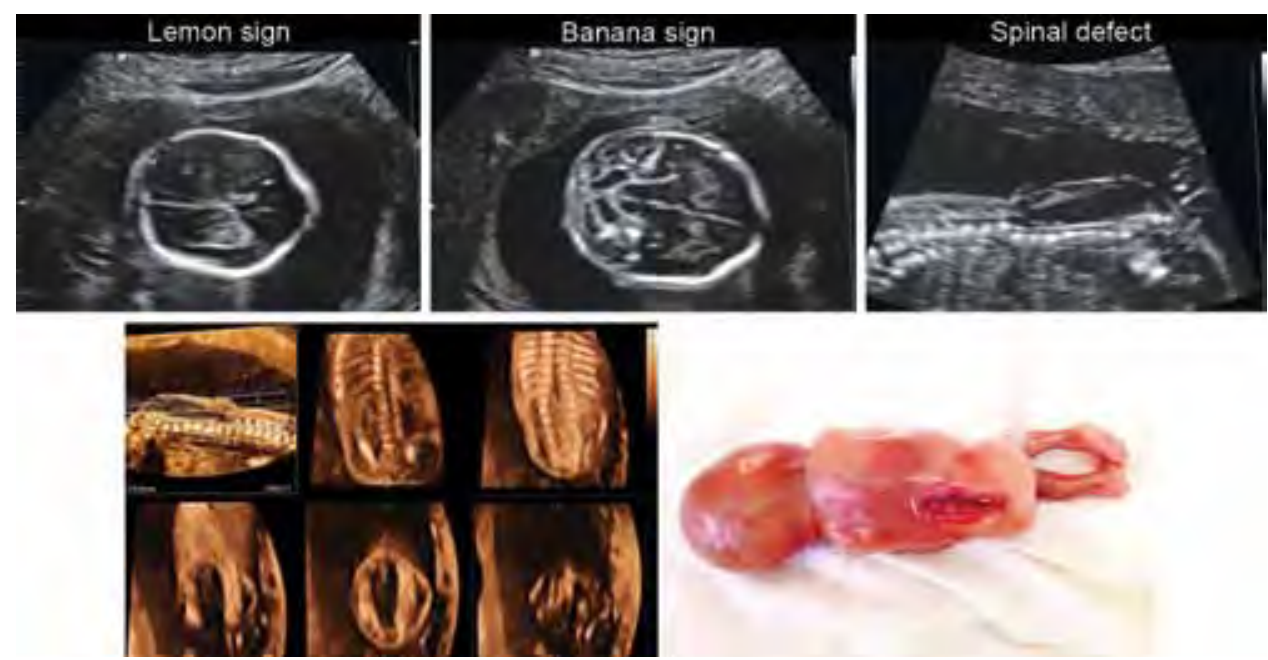

Fig. 9: Chiari malformation 
are found, and these are believed to be secondary to ventricular enlargement and brain stem compression.

Dislocation of the hip and foot deformities (clubfoot, rocker bottom foot) (Fig. 24) are frequently seen in association with spina bifida. The pathogenesis of the malformation is related to the unopposed action of muscle groups because of a defect of the peripheral nerve corresponding to the involved myotomes.

\section{Iniencephalia}

Iniencephaly is an NTD involving the occiput and inion combined with rachischisis of the cervical and thoracic spine with retroflexion of the head. ${ }^{27}$ Incidence is about 0.1 to 10 per 10000 . An extreme dorsal flexion of the head, the abnormally short and deformed cervical and thoracic spine and the overall shortening of the fetus are the key features in an sonographic scanning (Fig. 10).

\section{Cleft Lip and/or Palate}

The most common anomaly of the fetal face is cleft lip and/or palate. Because that the evaluation of the upper lip and anterior palate, or alveolar ridge of the maxilla, is important. Cleft lip and/or palate is common malformation that typically runs between the nostrils and may involve the central part of the posterior palate (Fig. 11). ${ }^{28}$ Linear defect extending from upper lip to the nostril. ${ }^{29}$ Midline clefts often associated with brain malformations (e.g. holoprosencephaly). Majority of cases have a multifactorial etiology and inheritance. ${ }^{29}$ Incidence is about $1 / 1000$ for cleft lip with or without cleft palate and about $5 / 1000$ for isolated cleft palate. ${ }^{28}$ Sixty percent of facial clefts are isolated. ${ }^{28}$

\section{Risk Factors}

Hyperthermia, chronic steroids, methotrexate, alcohol, hydantoin, trimethadione, and aminopterin, maternal rubella, phenylketonuria, folic acid deficiency and zinc deficiency. ${ }^{28}$

Cystic hygroma is congenital thin-walled cysts that contain lymphatic fluid commonly located in the soft tissue at the posterior neck region, but may extend cephalad to engulf the fetal head or caudad to cover the dorsum of the fetus, or may be found in the mediastinum and axilla (Fig. 12).
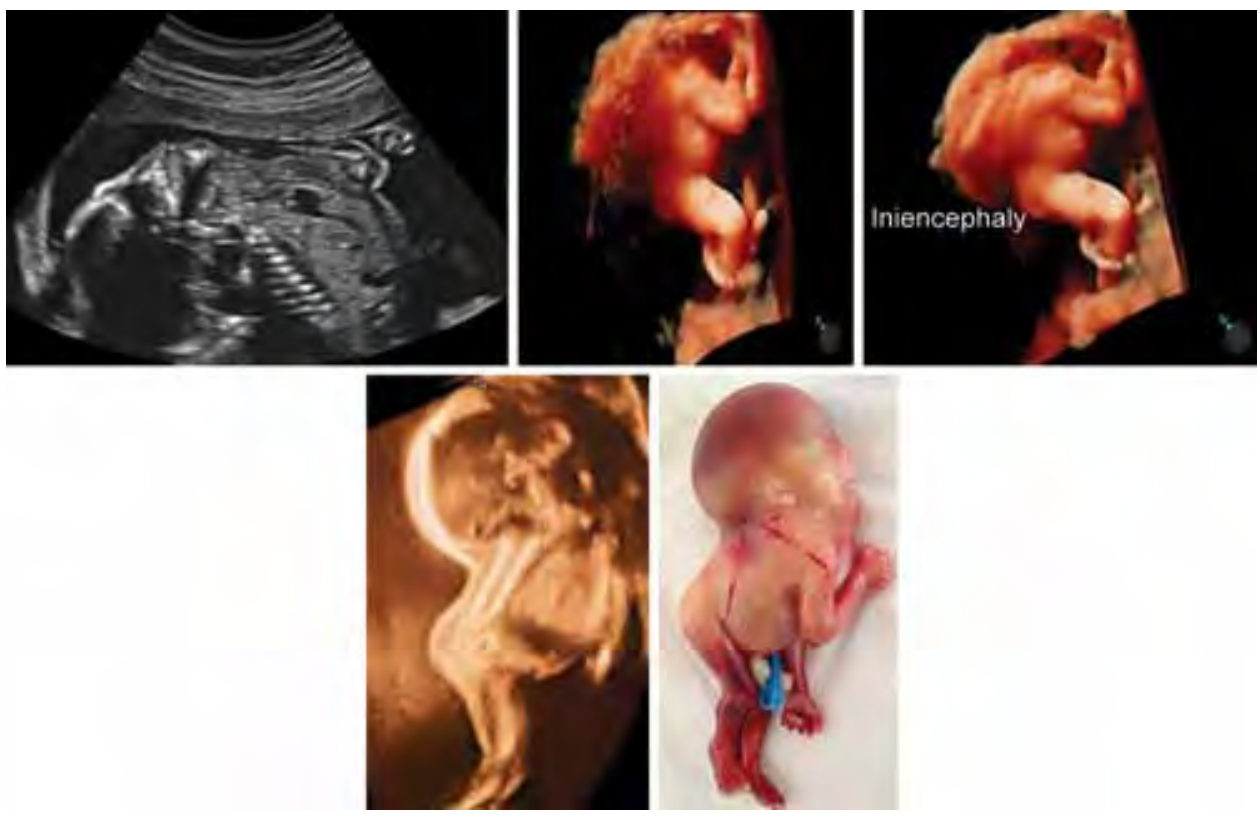

Fig. 10: Iniencephaly
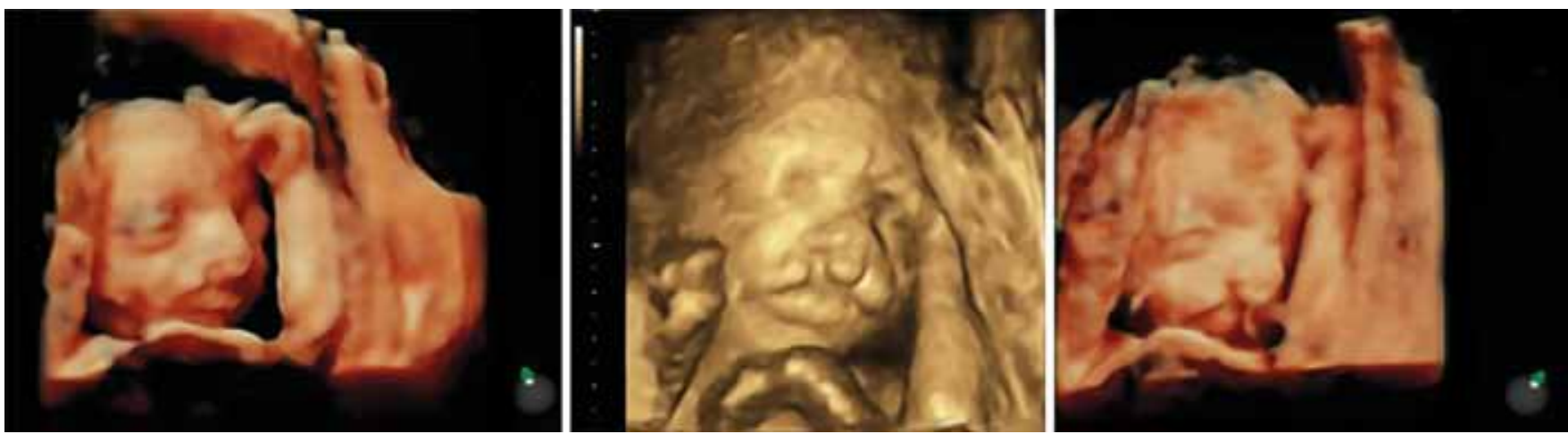

Fig. 11: Three-dimensional acquisition of unilateral and bilateral cleft lip 

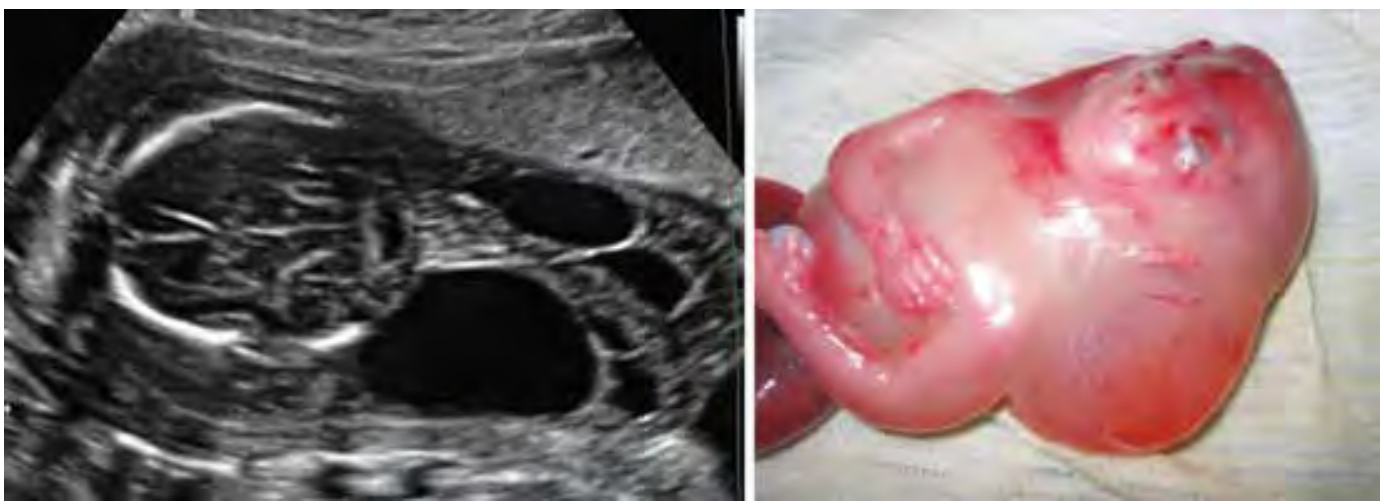

Fig. 12: Cystic hygroma

Incidence is about 1 in 100 pregnancies in first trimester. $^{30}$

The subclassification of septated cystic hygroma occurs in 1 in 285 pregnancies. $^{31}$

Arise from failure of primitive lymphatic tree to connect to the venous system. Blind lymphatic pouch results in dilation of the lymphatic sac. ${ }^{31}$

\section{Key Diagnostic Features}

Anechoic fluid-filled cavities that are encircled by soft tissue, usually located in the posterior neck. May be multiloculated with septations, or simple in appearance. May involve the fetal head, back, axilla, or mediastinum. A thick midline band may be present posteriorly, formed by the nuchal ligament separating the bilateral jugular lymphatic sacs (Fig. 12).

\section{Differential Diagnosis}

Thickened nuchal translucency, neural tube defects (posterior encephalocele, cervical meningocele), cystic teratoma, hemangioma, thyroglossal duct cysts, branchial cleft cysts.

\section{Associated Anomalies}

Associated structural anomalies seen in $33.8 \%$ of cases of first-trimester cystic hygromas. ${ }^{30}$ Aneuploidy (50\%): Trisomy $21(37.3 \%)$ is the most common chromosomal abnormality associated with cystic hygromas, followed by Turner syndrome (28.3\%), trisomy 18 (19.4\%), trisomy
$13(9.0 \%)$, and triploidy (4.5\%). ${ }^{30}$ Mosaic deletion of chromosomes has also been reported. ${ }^{30}$ Other associated anomalies include cardiac anomalies, skeletal abnormality, fetal hydrops, intrauterine fetal demise. Syndromes reported in fetuses with cystic hygroma include Roberts, Cornelia de Lange, multiple pterygium, and Noonan syndromes, and fetal akinesia sequence.

\section{Pleural Effusion}

Fetal pleural effusion is a nonspecific fluid collection in the pleural space. In chylothorax (or primary effusion), the fluid contains more than $1.1 \mathrm{mmol} / 1$ triglycerides (with oral fat intake) and has $<80 \%$ lymphocytes, but the term applies only to neonates, as the fetus is not fed in utero. Secondary effusions are those in which the fluid is clear, as in nonimmune hydrops. ${ }^{32}$ Fetal pleural effusion is sometimes referred to as hydrothorax. Incidence is $1: 10,000$ to $1: 15,000$, with male predominance. ${ }^{32-34}$

Normally, there is free movement of fluid between the mesothelial cells of the parietal pleura and the pleural space. The minute spaces between the mesothelial cells communicate directly with lymphatic channels, and these lymphatic channels drain into mediastinal lymph nodes. Any disruption of this drainage pathway results in a collection of lymphatic fluid in the pleural space (Fig. 13).

About 6 to $17 \%$ of cases with pleural effusion have aneuploidy. Sonographic findings are unilateral or bilateral anechoic space in the thorax, surrounding the lungs; best seen in transverse four-chamber heart view (Fig. 13). ${ }^{34}$ Bilateral fluid collections may evert the diaphragm. ${ }^{33}$
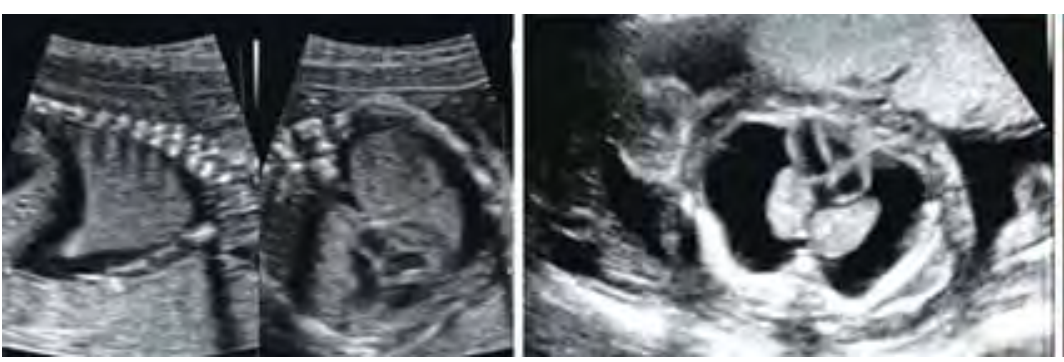

Fig. 13: Pleural effusion
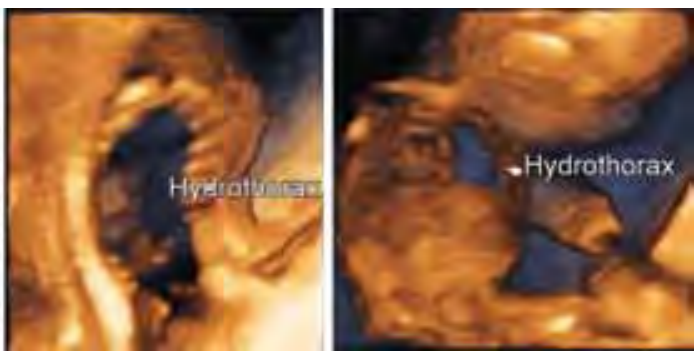
Primary effusion is usually unilateral which can rapidly progress but if it is small and unilateral, may spontaneously regress. Secondary effusion usually is bilateral, symmetric and in high association with immune and nonimmune hydrops.

\section{Anomalies associated with Hydrops}

Cystic hygroma, lung mass, other masses, cardiac abnormalities (structural defects and arrhythmias), polyhydramnios can develop also. First-trimester pleural effusions have been described and have a high association with chromosomal abnormalities. ${ }^{33}$

Bronchogenic cysts are cystic lesions lined by bronchial epithelium that may occur in mediastinum or lung. Prevalence is rare and they account for approximately $8 \%$ of mediastinal masses detected in children. ${ }^{35}$ Bronchogenic cysts arise due to abnormal budding of the tracheobronchial tree and foregut, in many cases as accessory lung buds of the ventral diverticulum of the foregut. ${ }^{35}$ About $15 \%$ of the cysts can occur in the lungs, others usually occurs in the middle mediastinum. Can be tiny or large-a few millimeters to more than $5 \mathrm{~cm}$, uni- or multilocular.

The cyst may be fluid filled or contain layering debris in the sonographic examination (Fig. 14). When they may be small and difficult to detect antenatally the effect of the cyst on the fetal lung can be much more conspicuous and serious. An enlarged obstructed fetal lung may be detected despite the fact that the obstructing cyst is not detected $^{36}$ or incorrectly diagnosed as another lesion such as CCAM. Exept CCAM in differential diagnoses of bronchogenic cyst may be included also neurenteric cyst and duplication cyst.

Congenital diaphragmatic hernia is a herniation of abdominal viscera into the fetal chest, which results from a congenital defect in the fetal diaphragm. Incidence is 2.4-4.9/10,000 and most are sporadic. By percentage 75\% are left-sided, $15 \%$ right-sided and $10 \%$ bilateral; in fetal demises, $47 \%$ are left-sided, 27\% right-sided and 27\% bilateral. $^{37}$

Results from abnormal diaphragm development at 6 to 10 weeks with incomplete closure of the pleuroperitoneal folds. Herniated viscera cause decreased bronchial branching, alveolar number, and pulmonary vascularization, and overmuscularization of pulmonary arterial tree, leading to pulmonary hypoplasia, pulmonary hypertension. ${ }^{38}$

Differential diagnosis include cystic lesions of the lung, specifically congenital cystic adenomatoid malformation (CCAM), especially types 1 and 2, and bronchopulmonary sequestration (BPS).

Key diagnostic Features are displaced heart and a thoracic mass (Fig. 15) - in left-sided CDH, the stomach appears as a cystic mass (Fig. 15) and is not seen in its normal position; liver is herniated in $50 \%{ }^{37}$

In almost all right-sided CDHs, the liver herniates; liver and lung have similar echogenicities, so a discrete mass is not always seen; diagnosis is suspected because of a mediastinal shift to the left. Doppler can show hepatic vascularity; gallbladder may be seen; MRI may
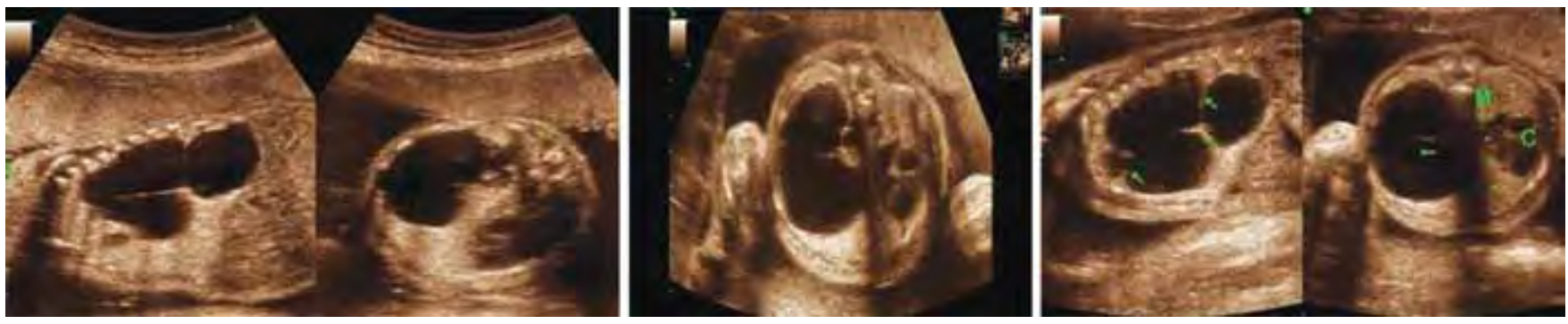

Fig. 14: Bronchogenic cysts
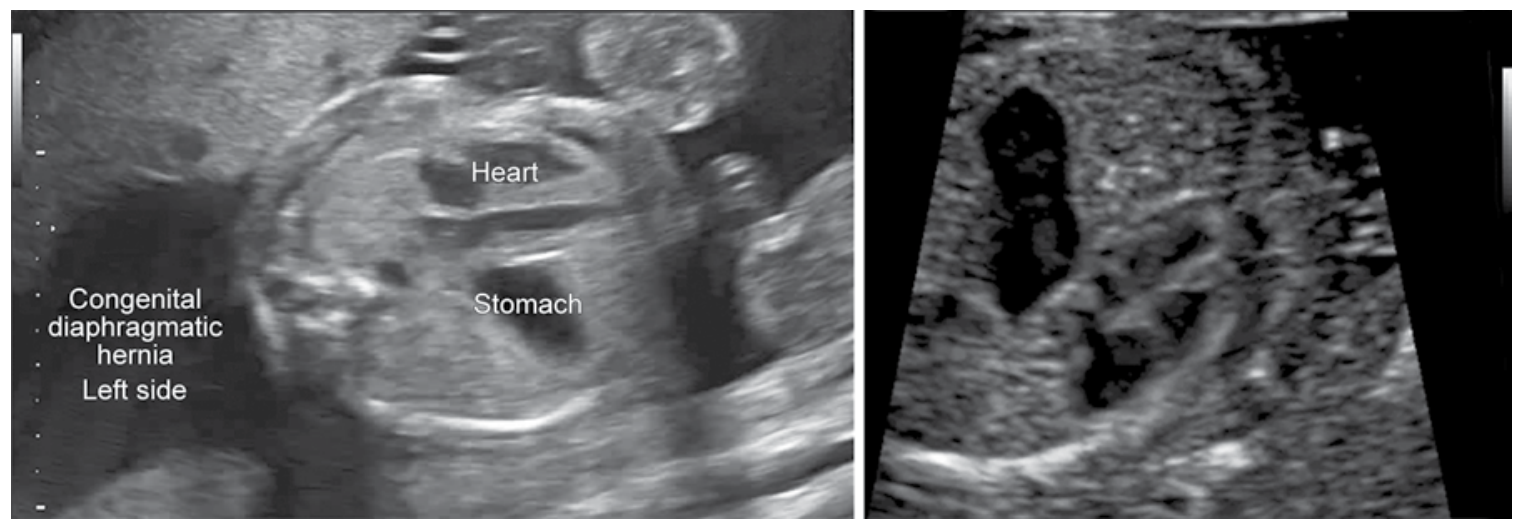

Fig. 15: Diaphragmatic hernia 
be useful. Abdominal circumference may be small, and the abdomen may appear scaphoid. Polyhydramnios results from esophageal compression and hydrops may follow. Depending on size of defect, herniated contents may change position over time.

\section{Abdominal Anomalies}

\section{Omphalocele}

Omphalocele is a midline ventral wall defect, with bowel or liver (or both) herniating through the base of the umbilicus and covered by a membrane consisting of peritoneum and amnion. The incidence of omphalocele is approximately $0.5-1 / 10,000$ live births. ${ }^{39}$ Omphalocele results from a defect in the lateral folding in the embryo, with failure of abdominal wall closure at the umbilical ring and persistence of intestinal loops or liver (or both) in the umbilical cord stalk after physiologic gut herniation.

Risk factors for developing omphalocele include advanced maternal age ( $>35$ years) and assisted reproductive technology (ART). ${ }^{39}$

\section{Differential Diagnosis}

Normal physiologic gut herniation-never includes liver, gastroschisis, limb-body wall complex, umbilical hernia, umbilical cord cysts and pseudocysts, allantoic cyst, bladder or cloacal exstrophy. ${ }^{40}$

Midline mass is seen at the base of the umbilical cord, with the liver and bowel herniating from the abdominal cavity, surrounded by a smooth, limiting membrane. The umbilical cord passes through the mass and inserts on the membranes (Fig. 16). This key feature distinguishes omphalocele from gastroschisis in cases of ruptured omphalocele sac. Ascites may be seen in the omphalocele sac. The absence of liver in the omphalocele sac (intracorporeal liver) is strongly associated with aneuploidy. Maternal serum $\alpha$-fetoprotein is not uniformly elevated with omphalocele.

\section{Gastroschisis}

Is a full-thickness paraumbilical defect through which bowel herniates, not enveloped by a membrane. The incidence is approximately 5/10 000 live births. ${ }^{41}$ The embriogenesis is unclear.

During scanning multiple loops of bowel are seen floating freely in the amniotic fluid, with typical cauliflower appearance (Fig. 17). Defect is typically located at the right of the abdominal cord insertion.

The bowel-related abnormalities are the most common and the more clinically important complications related to gastroschisis. ${ }^{41}$ Differentiation from omphalocele and cloacal extrophy is needed. The combination of omphalocele, exstrophy of the bladder, imperforate anus, and spinal deformities has been called the OEIS complex, a rare disorder, affecting 1 in 200000 to 400000 pregnancies. ${ }^{41}$ Also, limb-body-wall complex (Fig. 18) sometimes have been misdiagnosed as omphalocele or gastroschisis. LBWC comprises a number of complex defects commonly including abdominothoracic defects, scoliosis, and limb defects.

Esophageal atresia is a disruption of the esophagus, producing a blind-ending esophageal pouch or tracheoesophageal fistula (or both), and resulting in a small or absent stomach bubble.

The incidence of esophageal atresia is approximately 3/10,000 live births. ${ }^{42}$ Esophageal atresia is a multifactorial, sporadic condition involving genetic predisposition and environmental exposures (e.g. alcohol, smoking, medications, infections, agricultural chemicals).
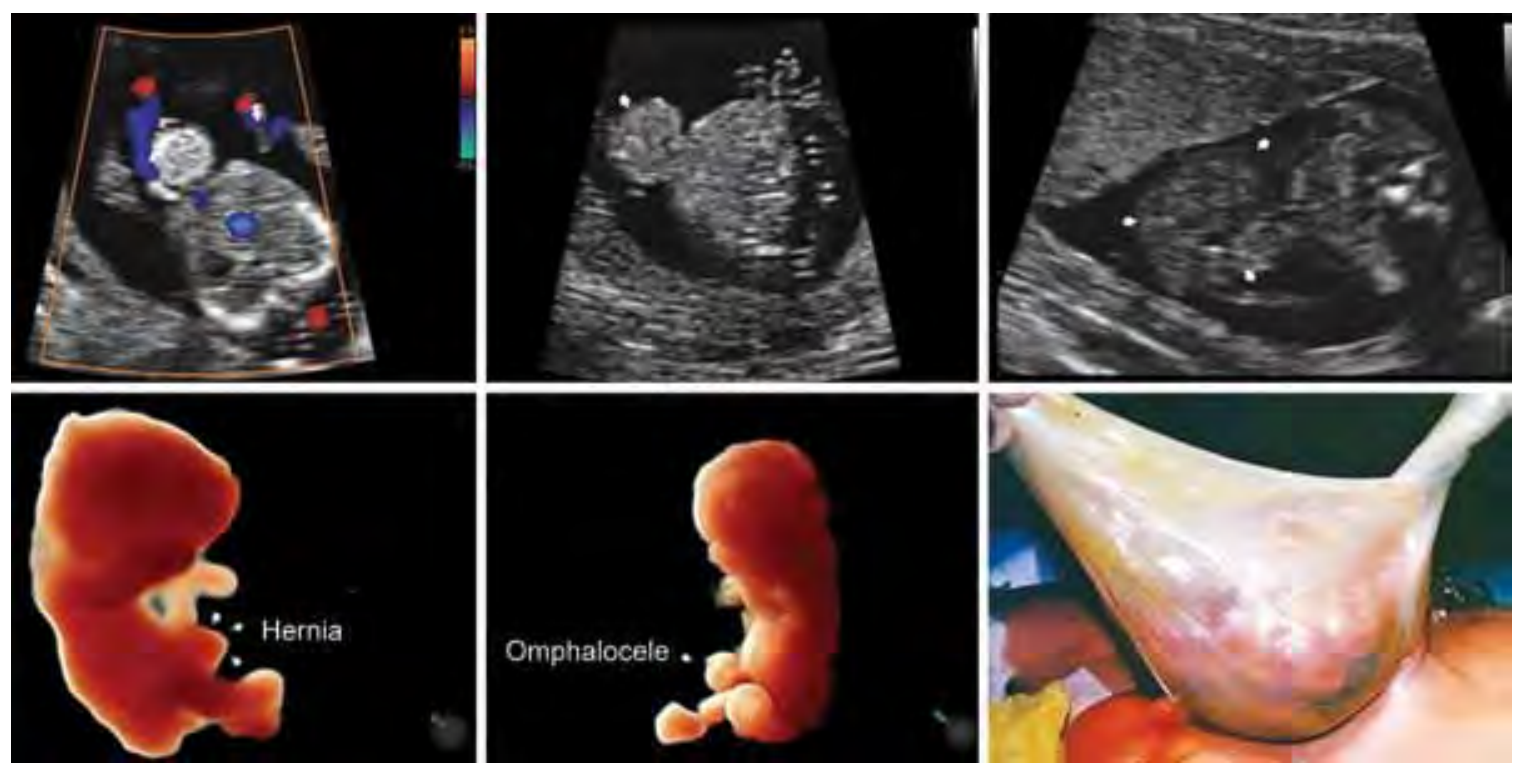

Fig. 16: Omphalocele 

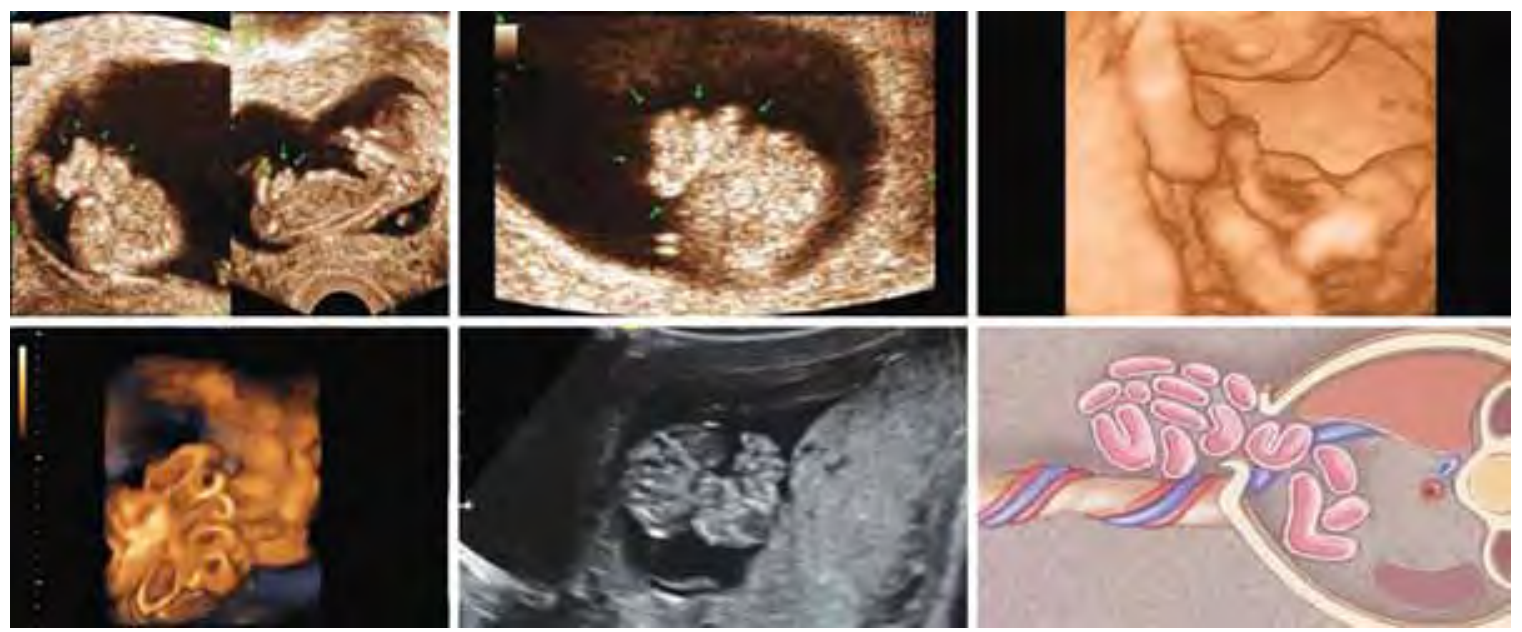

Fig. 17: Gastroschisis
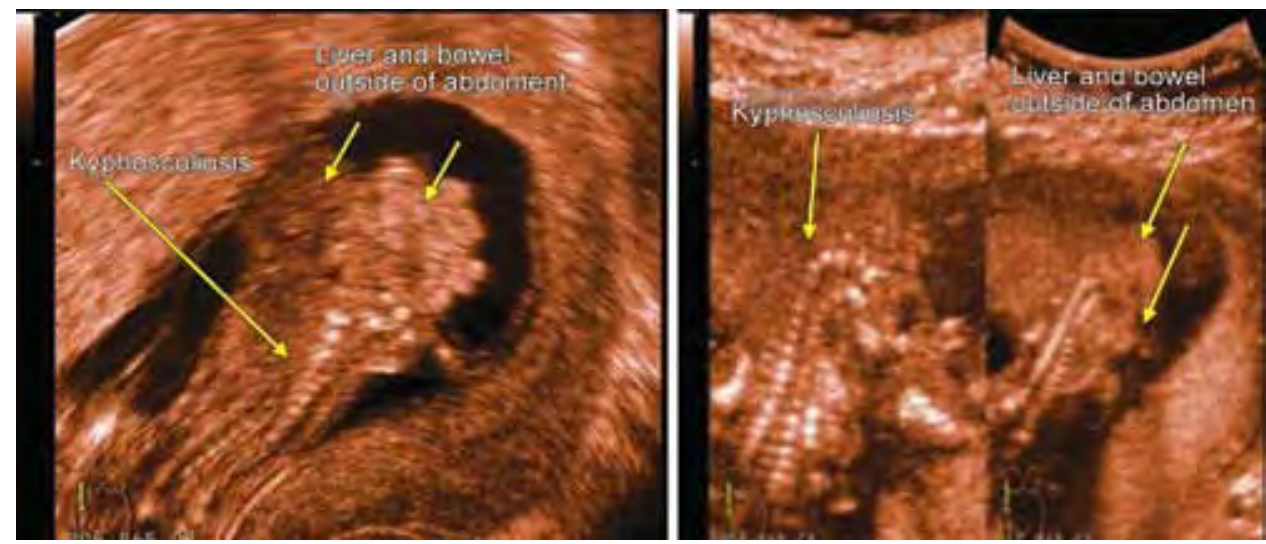

Fig. 18: Limb-body wall complex

\section{Differential Diagnosis}

Other conditions appearing with absent or small stomach on ultrasound: Congenital diaphragmatic hernia, chest masses (e.g. cystic adenomatoid malformation), ventral wall defects, fetal neuromuscular disorders, oligohydramnios (with or without intrauterine growth restriction). During the scan persistent lack of sonographic stomach visualization (Fig. 19) after the 14th week of gestation should prompt a thorough ultrasound assessment. Esophageal atresia is suspected when there is a persistent absent or diminutive stomach bubble, despite prolonged and repetitive imaging, with concomitant polyhydramnios, particularly in the third trimester. ${ }^{43}$ A 'pouch sign' may be present, indicating a dilated upper esophagus, posterior to a fluid-filled trachea. Tracheoesophageal fistula commonly accompanies esophageal atresia, with $86 \%$ of fetuses presenting with a proximal esophageal atresia and a distal tracheoesophageal fistula. ${ }^{42}$ This allows fluid to pass into the stomach, making prenatal diagnosis difficult.

\section{Associated Anomalies}

Polyhydramnios is present in two thirds of cases of esophageal atresia. Approximately $80 \%$ of patients with esophageal atresia have other associated anomalies, cardiac, urogenital, musculoskeletal, craniofacial and neurologic. Also, esophageal atresia can be part of a syndrome [VATER syndrome (vertebral defects, imperforate anus, tracheoesophageal fistula, renal defects), or VACTERL association [vertebral abnormality, anal atresia, cardiac defect, tracheoesophageal fistula, renal and radial limb abnormality)], and aneuploidy (trisomy 18, 21). ${ }^{42}$

\section{Urogenital Anomalies}

The incidence of antenatally detected urinary tract abnormalities varies among centers and depends on the timing of the scan. Scanning later in pregnancy detects a higher proportion of urinary tract anomalies. ${ }^{44}$ Assessment of the urinary tract involves the fetal kidneys, bladder and liquor volume. The absence of the kidney (Fig. 20A) should prompt a search for a kidney in an ectopic location, most commonly in the fetal pelvis. If there is no pelvic kidney then unilateral renal agenesis (Fig. 20A) is the most likely diagnosis. If both kidneys are absent severe oligohydramnios associated with absence of the bladder is usually seen. The presence of macroscopic cysts affecting a kidney usually indicate a multicystic dysplastic kidney (Fig. 20B). If unilateral disease liquor 

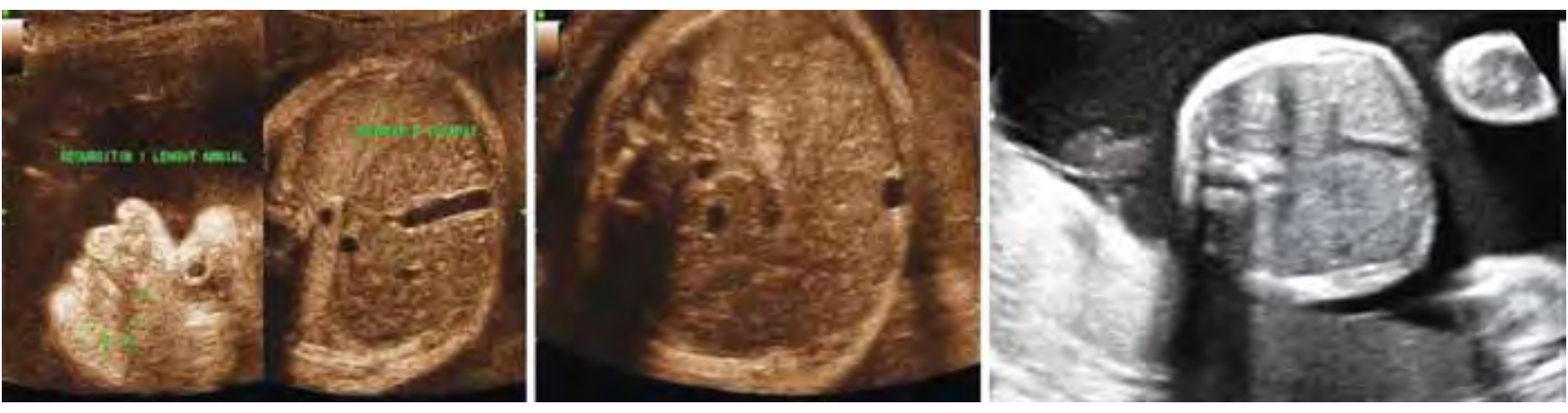

Fig. 19: Esophageal atresia - the stomach is not visible

volume is normal. Care should be taken not to confuse this condition with hydronephrosis (Fig. 20C). In this situation it is important to demonstrate that the cysts do not communicate, ${ }^{44,45}$ because this finding is more indicative of hydronephrosis.

Large echogenic kidneys usually indicate either infantile polycystic renal disease or occasionally adulttype polycystic disease. Liquor volume is usually reduced in the former but normal in the latter. Dilatation of the renal collecting system suggests either hydronephrosis or reflux. Initially the affected kidney is scrutinized, and if the dilatation affects just the upper pole of the kidney then there may be a duplex system. In that setting the bladder is assessed with a view to demonstrate a ureterocele (Fig. 20D). The level of obstructions is determined by the degree of dilatation of the renal pelvis (Fig. 20G) and
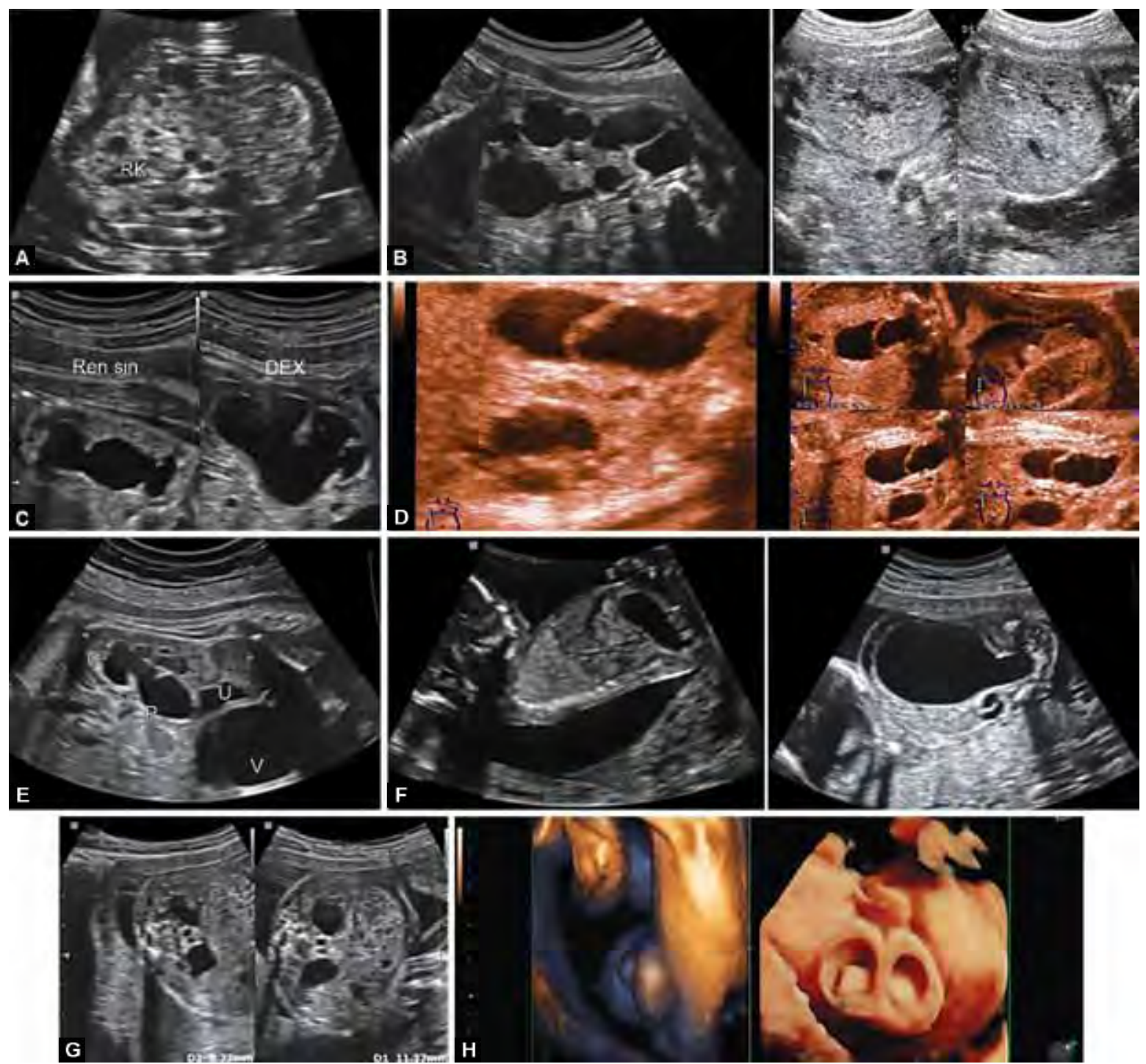

Figs 20A to H: Different aspects of urogenital fetal anomalies: (A) Unilateral renal agenesis, (B) polycystic kidney disease, (C) hydronephrosis, (D) ureterocele, (E) Megaureter, (F) urethral atresia at 14 and 18 weeks, (G) pyelectasia, (H) hypospadia 
ureter. Dilatation of the renal pelvis usually only indicates a pelviureteric junction obstruction, whereas ureteric dilatation (Fig. 20E) suggests either a vesicoureteric junction obstruction or reflux.

Bilateral hydronephrosis should always raise the possibility of bladder outlet obstruction and ureteric dilatation should be present. The bladder wall may be thickened with dilatation of the posterior urethra (Fig. 20F). Bilateral hydronephrosis and hydroureters can be associated with vesicoureteric reflux and in this case even though the bladder may be distended the wall is usually not thickened and liquor volume is normal. ${ }^{45}$ Hypospadias (Fig. 20H) is an anomaly of the male urogenital tract as a result of failure of complete development of the anterior urethra. ${ }^{45}$ Care should be taken not to confuse with ambigual genitalia.

\section{Skeletal Dysplasias}

The skeletal dysplasias are a large heterogenous group of genetic conditions characterized by abnormal shape, growth or integrity of bones. The birth prevalence has been estimated to be 2.4 for 10000 births. ${ }^{46}$ The four most common skeletal dysplasias are thanatophoric dysplasia, achondroplasia osteogenesis imperfecta, and achondrogenesis. ${ }^{46}$ Mostly of the skeletal dysplasias are lethal and achondroplasia is the most nonlethal one.

When the limb shortening is identified, it can be characterized as involving the entire limb (micromelia), the proximal segment (rhizomelia), the intermediate segment (mesomelia), or the distal segment (acromelia) (Fig. 21). Abnormalities of the hand and feet are important clues to the type of skeletal dysplasia. They may be polydactyly, which can be preaxial or postaxial, syndactyly, and clinodactyly. Clubbing of the hand is very suggestive of radial ray anomalies (Fig. 22) which can be in range from abnormal thumbs (sometimes triphalangeal as in Holt-Oram syndrome) to hypoplasia or absence of the thumb and sometimes absence of the radius or even the radius and the hand. At the level of the feet a rockerbottom foot or a clubfoot should also be sought.

Osteogenesis imperfecta is a heterogeneous group of genetic disorders characterized by severe bone fragility leading to abnormal ossification and multiple fractures ${ }^{47}$ classically divided in four types by Silence: I, II or congenital, III and IV. Incidence is 0.4 per 10000 births and aproximately a half is type II. ${ }^{47}$ The sonographic findings that may be present (particularly in type II) include broad, short, fractured long bones with a wrinkled appearance caused by callus formation; decreased ossification of the scull with increased visualization of the intracranial structures; small bell-shaped chest; irregular ribs due to rib fractures ; abnormal scull shape; broad irregular ribs angulation of the long bones; and abnormal face (Fig. 23). Multiple fractures are present by birth.

Congenital clubfoot is a malformation of the fetal ankle producing various abnormal posturings of the foot.
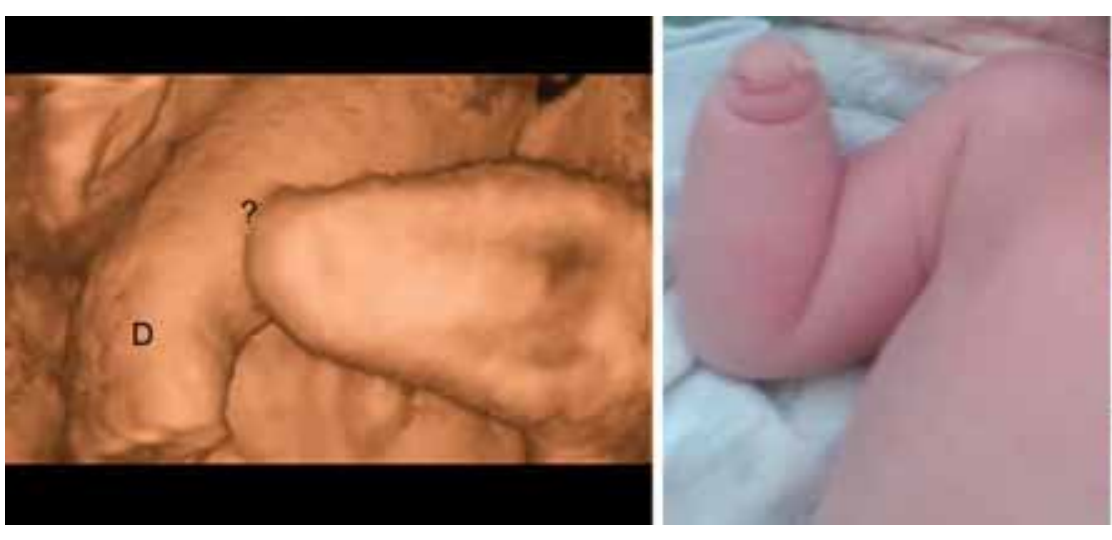

Fig. 21: Acheiria
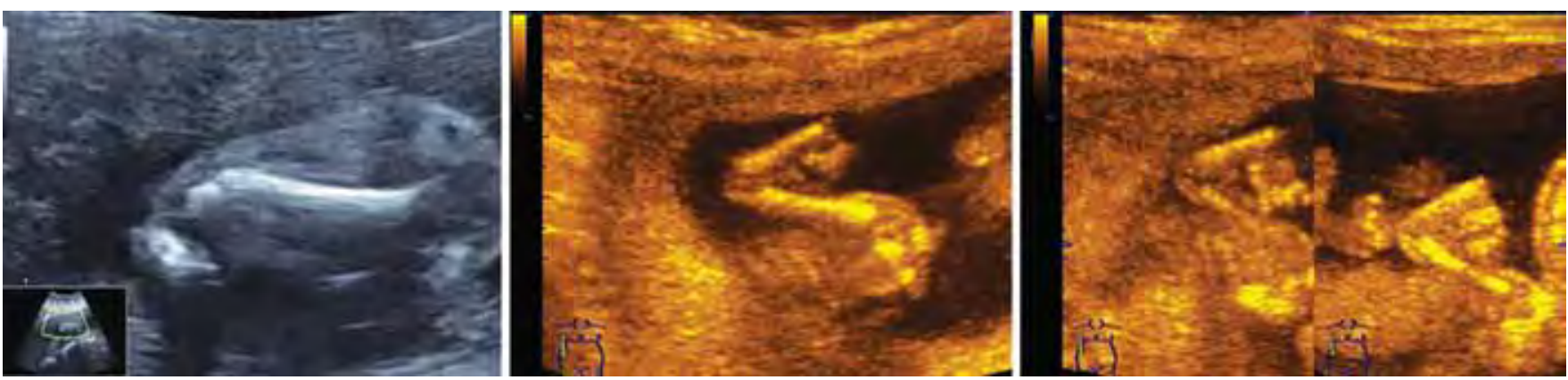

Fig. 22: Radius aplasia

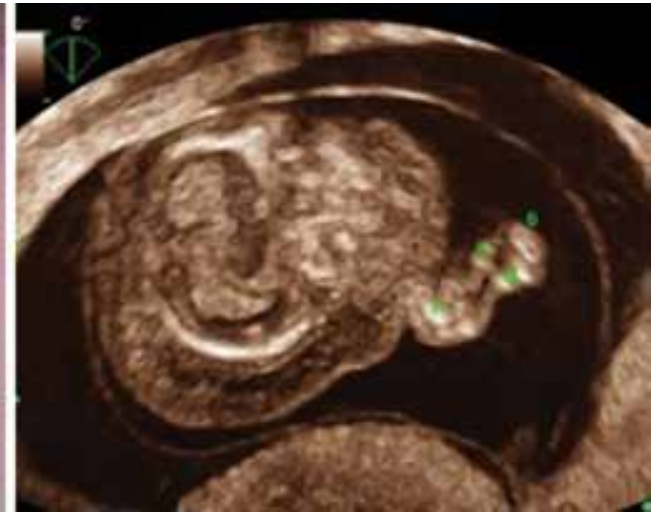

.

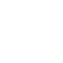



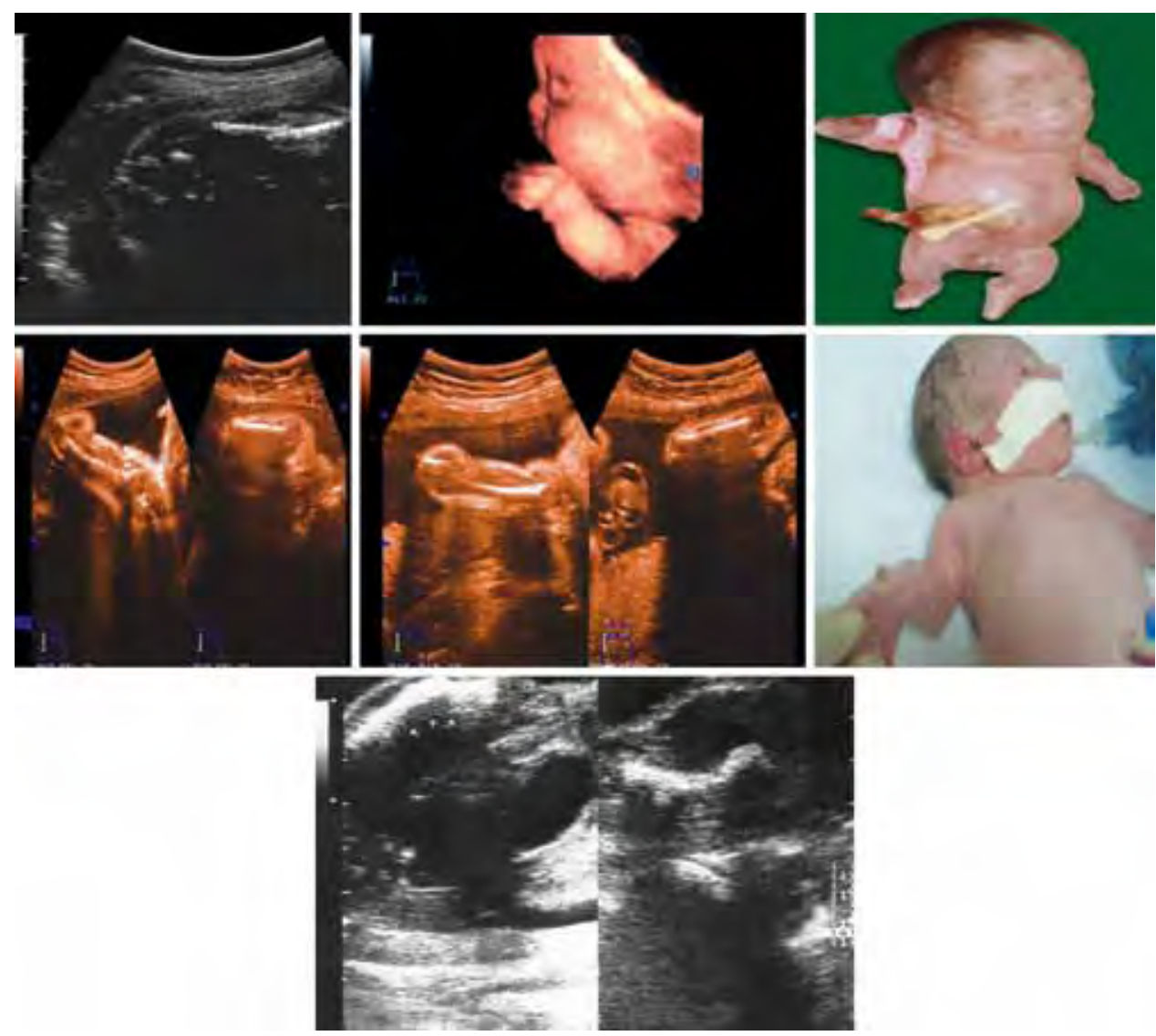

Fig. 23: Osteogenesis imperfecta

The incidence is approximately 1-3/1000 live births, the male-to-female ratio is $2: 1 .{ }^{46}$ Usually are bilateral, only one third is unilateral. Etiology is multifactorial, with disruption of the neuromuscular unit and unopposed muscle activity restricting the ankle in a distorted position.

Clubfoot deformity is diagnosed when both the tibia and the fibula are seen in coronal plane with the sole of the foot visible in the same plane (Fig. 24), and this persists during the course of the ultrasound examination. A falsepositive rate for prenatal diagnosis of clubfoot is up to $30 \%$.

\section{Fetal Tumors}

Sacrococcygeal teratoma (SCT) is a germ cell tumor extending from the presacral area. Sacral agenesis (caudal regression) is a lack of embryonic development of the sacrum and lower spine. Incidence of SCT occurs in $1 / 40,000$ live births with a male-to-female ratio of $1: 3^{48,49}$ and sacral agenesis occurs in 1-5/100,000 live births; classically reported in approximately $1 \%$ of diabetic pregnancies. $^{49}$

\section{Differential Diagnosis}

Meningocele/meningomyelocele, lipoma, sirenomelia, vestigial tail, arthrogryposis, imperforate anus, amniotic band syndrome, bladder outlet obstruction. Sacrococcygeal teratoma appears as a solid or cystic mass extending from the coccyx to beyond the perineum (Fig. 25). Color Doppler imaging may show high-volume, high-velocity flow. Magnetic resonance imaging is useful to determine extent of intrapelvic extension.
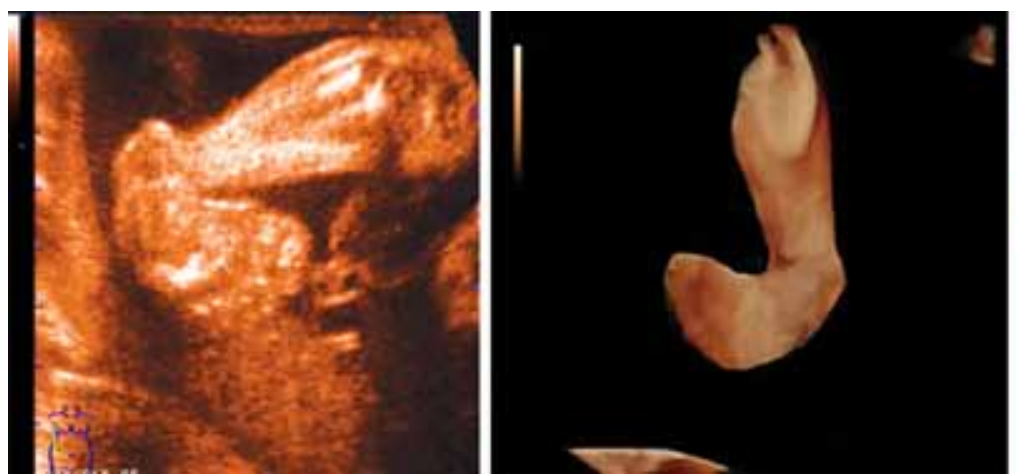

Fig. 24: Clubfoot

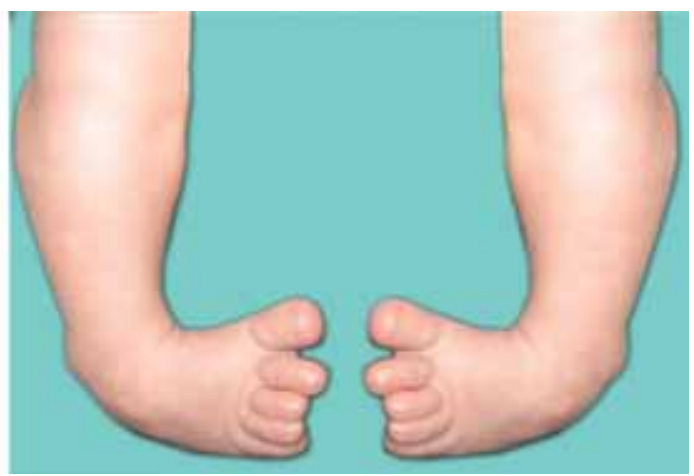



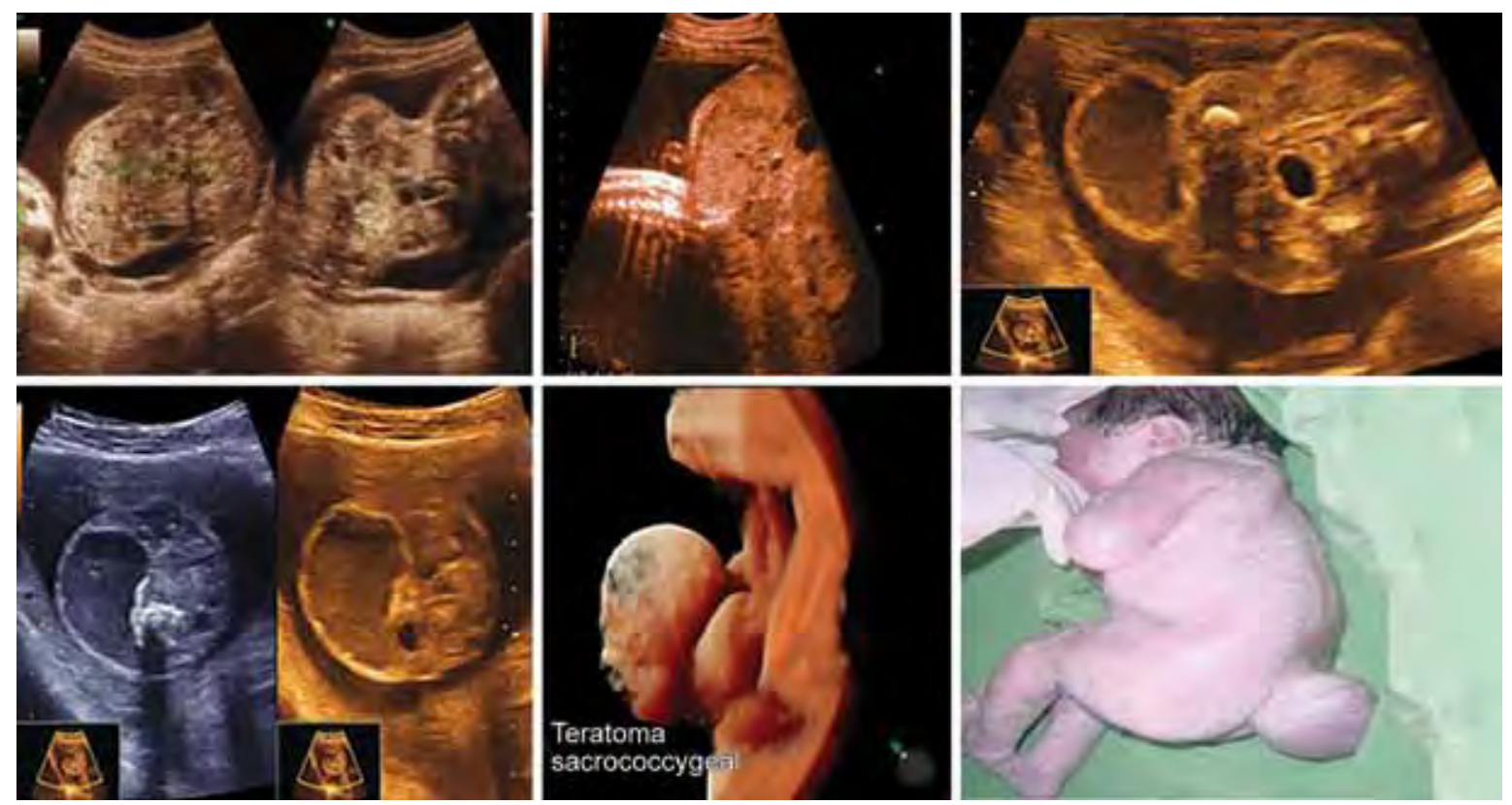

Fig. 25: Sacrococcygeal teratoma

American academy of pediatric surgery ${ }^{50}$ distinguish four types of sacrococcygeal teratoma:

- Type I-External tumor with minimal presacral involvement.

- Type II-External tumor with intrapelvic extension

- Type III-External tumor with pelvic mass extending into abdomen

- Type IV—Presacral mass with no external component.

Sacral agenesis appears as an abruptly ending lower spine on sagittal imaging, confirmed on axial view.

Fetal intracranial tumors are rare. The incidence has been estimated at 0.34 per 1 million births. ${ }^{51}$ Teratomas are the most frequent tumors and other types are neuroepithelial tumors, lipomas, craniopharyngioma, etc. Most of the lesions are supratentorial ${ }^{52}$ and suspicion for cranial tumors is occurred when mass-occupying lesion, cystic or solid areas, are seen within the fetal head or when there is a change in shape or size of the normal anatomic structures (Fig. 26).

\section{Conjoined Twins}

Conjoined twins are a subset of monozygotic twin gestations in which incomplete embryonic division occurs 13 to 15 days after conception, resulting in varying degrees of fusion of the two fetuses. The estimated frequency of conjoined twinning is 1.5 in 100,000 births. ${ }^{53}$ The prenatal diagnosis should be straightforward and is confirmed by failure to visualize two fetuses separately (Fig. 27) in what appears to be a single amniotic sac. Other sonographic features that assist in making the diagnosis include bifid appearance of the first-trimester fetal pole, more than three umbilical cord vessels, heads persistently at the same level and body plane, and failure of the fetuses to change position relative to each other over time. ${ }^{54}$

Prenatal diagnosis of conjoined twins has been made in the first trimester with the aid of 3D sonography. ${ }^{55}$ However, caution should be exercised in making a definite diagnosis of conjoined twins at less than 10 weeks' gestation, because false-positive diagnoses have
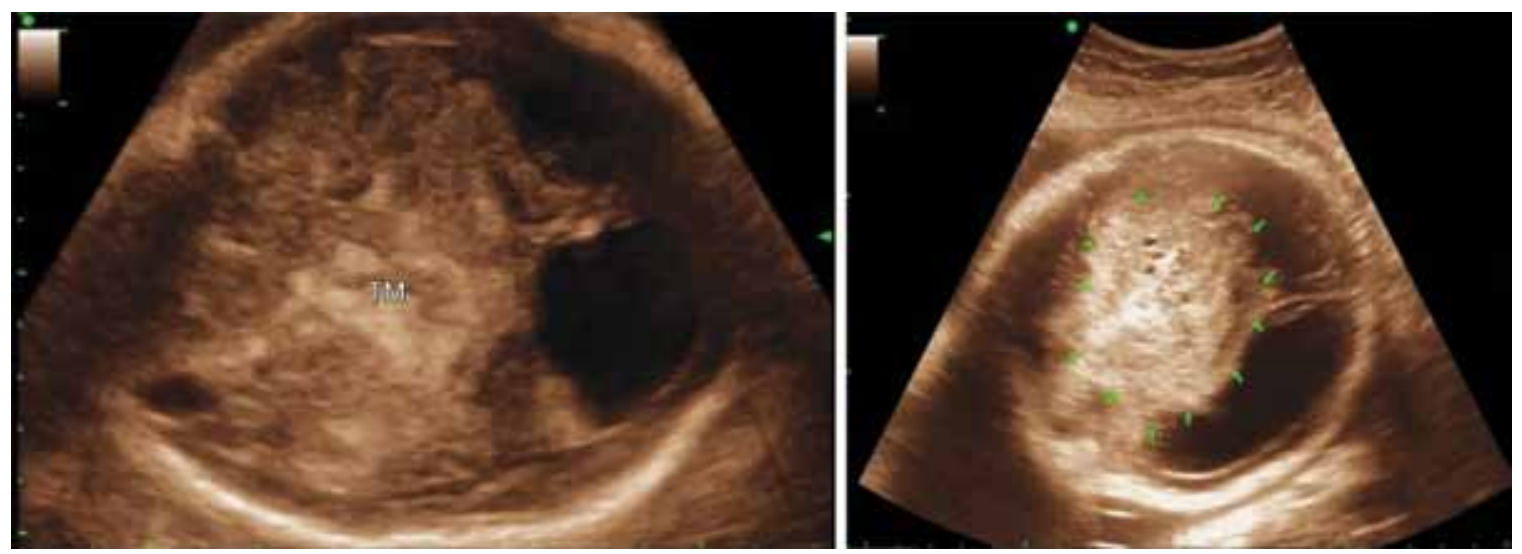

Fig. 26: Intracranial tumor 

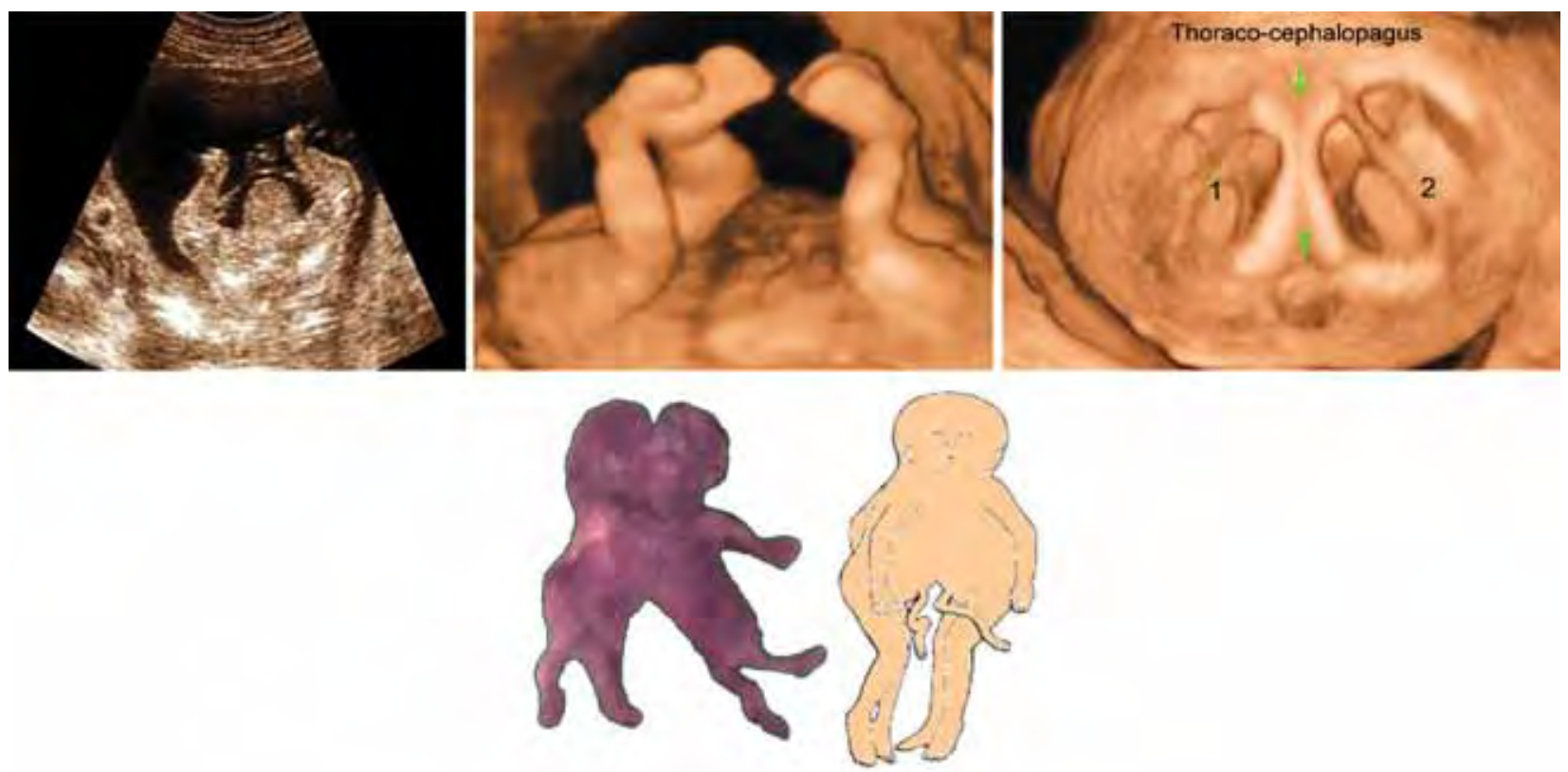

Fig. 27: Conjoined twins

been documented. ${ }^{56}$ By careful sonographic survey of the shared anatomy, it should be possible to classify conjoined twins into one of the following five types:

1. Thoracopagus, in which the two fetuses face each other, accounts for $75 \%$ of conjoined twins. The fetuses usually have common sternum, diaphragm, upper abdominal wall, liver, pericardium, and gastrointestinal tract. Because $75 \%$ of thoracopagus twins have joined hearts, prognosis for surgical division is extremely poor.

2. Omphalopagus (or xiphopagus) is a rare subgroup of thoracopagus in which there is an abdominal wall connection, often also with a common liver.

3. Pygopagus accounts for $20 \%$ of cases; the twins share a common sacrum and face away from each other. There is a single rectum and bladder, and prognosis for surgical separation is usually good.

4. Ischiopagus, in which the twins share a single common bony pelvis, accounts for $5 \%$ of conjoined twins. Surgical prognosis is good, although the remaining lower spines are often abnormal.

5. Craniopagus accounts for $1 \%$ of cases and is marked by partial or complete fusion of skull, meninges, and vascular structures. Surgical prognosis depends on the degree of fusion of vascular structures, in particular the presence of a superior sagittal sinus adequate to allow venous drainage. ${ }^{55}$

\section{CONCLUSION}

After all of these years of work in antenatal care and fetal wellbeing we can conclude that ultrasound application for fetal surveillance is one of the most important tool for evaluation of fetal wellbeing and diagnosing of different, major and minor, disturbances which, if are detected on time can rescue the mother and fetal life by changing the way of managing of pregnancy and delivery.

\section{REFERENCES}

1. Gliozheni O, Sylejmani S, Kati K. Ultrasound and diagnosis of fetal anomalies. Donald School J Ultrasound in Obstet Gynecol 2011;5(3):193-204.

2. Kalter $\mathrm{H}$, et al. Congenital malformations. Etiological factors and their role in prevention. N Engl J Med 1983;308(8):424-431.

3. Levi S, et al. End-result of routine US screening for congenital anomalies. The Belgian multicentric study. US Obstet Gynecol 1995;5(6):366-371.

4. Lynberg MC, et al. Evaluation of the birth-defects monitoring program, 1982-1985, Teratology 1993;48(6):650-657.

5. Queisser Luft A, et al. Prenatal diagnosis of major malformations. Prenat Diag 1998;18(6):567-576.

6. McIntosh R, Merrit K, Richards M. The incidence of congenital anomalies. A study of 5,964 pregnancies. Pediatrics 1954;14(5):505-522.

7. Creasy MR, Alberman ED. Congenital malformations of the central nervous system I. Spontaneous abortions. J Med Genet 1976;13(1):9-16.

8. Singh PR, Carr DH. Anatomic findings in human abortions of known chromosomal constitution. Obstet Gynecol 1967;29(6):806-818.

9. Limb CJ, Holmes LB. Anencephaly: changes in prenatal detection and birth status, 1972 through 1990. Am J Obstet Gynecol 1994;170(5 pt 1):1333-1338.

10. Deak KL, Siegel DG, George TM, et al. Further evidence for a maternal genetic effect and a sex-influenced effect contributing to risk for human neural tube defects. Birth Defects Res A Clin Mol Teratol 2008;82(10):662-669.

11. O'Rahilly R, Müller F. Human embryology and teratology. 3rd ed. New York: Wiley-Liss; 2001.

12. Marin-Padilla M. Cephalic axial skeletal-neural dysraphic disorders: embryology and pathology. Can J Neurol Sci 1991; 18(2):153-169. 
13. Müller F, O'Rahilly R. Cerebral dysraphia (future anencephaly) in a human twin embryo at stage 13. Teratology 1984;30(2):167-177.

14. Müller F, O'Rahilly R. Development of anencephaly and its variants. Am J Anat 1991;190(3):193-218.

15. Naidich TP, Altman NR, Braffman BH, McLone DG, Zimmerman RA. Cephaloceles and related malformations. Am J Neuroradiol 1992;13(2):655-690.

16. Cardosa JD, Goldstein RB, Filly RA. Exclusion of fetal ventriculomegaly with a single measurement: the width of the lateral ventricular atrium. Radiol 1988;169(3):711-714.

17. Cronan MS, McGahan JP. A new ultrasound technique to visualize the proximal fetal cerebral ventricle. J Diagn Med Sonography 1991;6(6):333-335.

18. DeMyer W. In: Vinken PJ, Bruyn GW, editors. Handbook of clinical neurology. Amsterdam, Elsevier, 1977;30:431.

19. Filly RA, Chinn DH, Callen PW. Alobar holoprosencephaly. Ultrasonographic prenatal diagnosis. Radiol 1984;151(2):455-459.

20. Pilu G, Recce EA, Romero R, Bovicelli I, Hobbins JC. Prenatal diagnosis of craniofacial malformations by sonography. Am J Obstet Gynecol 1986;155(1):45-50.

21. Nyberg DA, McGahan JP, Pretorius DH, Pilu G. Diagnostic imaging of fetal anomalies. Lippincott Williams \& Wilkins 2003;6:269.

22. NybergDA,McGahanJP,Pretorius DH,PiluG. Diagnostic imaging of fetal anomalies. Lippincott Williams \& Wilkins 2003;6:257.

23. Pilu G, Visentin A, Valeri B. The dandy-Walker complex and fetal sonography. Ultrasound Obstet Gynecol 2000;16(2):115-117.

24. Achiron R, Achiron A. Transvaginal ultrasonic assessment of the early fetal brain. Ultrasound Obstet Gynecol 1991;1(5):336-344.

25. Babcook CJ, Chong BW, Salamat MS, Ellis WG, Goldstein RB. Sonographic anatomy of the developing cerebellum: normal embryology can resemble pathology. Am J Rentgenol 1996; 166(2):427-433.

26. Nyberg DA, Mahony BS, Hegge FN, Hickok D, Luthy DA, et al. Enlarged cisterna magna and the Dandy-Walker malformation: factors associated with chromosome abnormalities. Obstet Gynecol 1991;77(3):436-442.

27. Timor-Tritsch IE, Monteagudo A, Pilu G, et al. Chapter 5: Disorders of dorsal induction. Timor-Tritsch IE Monteagudo A Pilu G, et al. Ultrasound of the prenatal brain. 3rd ed. 2012 McGraw-Hill Professional New York.

28. Mossey PA, Little J, Munger RG, et al. Cleft lip and palate. Lancet 2009;374(9703):1773-1785.

29. Bianchi D, Crombleholme T, D'Alton M, et al. Fetology: diagnosis and management of the fetal patient. 2nd ed. 2010 McGraw Hill New York.

30. Podobnik M, Singer Z, Podobnik-Sarkanji S, et al. First trimester diagnosis of cystic hygromata using transvaginal ultrasound and cytogenetic evaluation. J Perinat Med 1995;23(4):283-291

31. Malone FD, Ball RH, Nyberg DA, et al. First-trimester septated cystic hygroma: prevalence, natural history and pediatric outcome. Obstet Gynecol 2005;106(2):288-294.

32. Rustico MA, Lanna M, Coviello D, et al. Fetal pleural effusion. Prenat Diagn 2007;27:793-799.

33. Sanders RC, Blackmon LR, Hogge WA, et al. Structural fetal abnormalities: the total picture 2nd ed. Mosby St Louis 2002.

34. Woodward PJ, Kennedy A, Sohaey R, et al. Diagnostic imaging: obstetrics. 2nd ed. Lippincott Williams \& Wilkins Hagerstown, Md 2011.

35. Pare JAP, Fraser RG. Synopsis of diseases of the chest, Philadelphia, WB Saunders, 1983;863.
36. Young G, L'Heuroux PR, Krueckeberg ST, Swanson DA. Mediastinal bronchogenic cyst: prenatal sonographic diagnosis. Am J Rentgenol 1989;152:125-127.

37. Logan JW, Rice HE, Goldberg RN, et al. Congenital diaphragmatic hernia: a systematic review and summary of best-evidence practice strategies. J Perinatol 2007;27:535-549.

38. Gallot D, Boda C, Ughetto S, et al. Prenatal detection and outcome of congenital diaphragmatic hernia: a French registry-based study. Ultrasound Obstet Gynecol 2007;29: 276-283.

39. Brantberg A, Blaas HG, Haugen SE, et al. Characteristics and outcome of 90 cases of fetal omphalocele. Ultrasound Obstet Gynecol 2005;26:527-537.

40. Groves R, Sunderajan L, Khan AR, et al. Congenital anomalies are commonly associated with exomphalos minor. J Pediatr Surg 2006;41:358-361.

41. David AL, Tan A, Curry J. Gastroschisis: sonographic diagnosis, associations, management and outcome. Prenat Diagn 2008;28:633-644.

42. Brantberg A, Blaas HG, Haugen SE, et al. Esophageal obstruction-prenatal detection rate and outcome. Ultrasound Obstet Gynecol 2007;30:180-187.

43. Houben $\mathrm{CH}$, Curry JI. Current status of prenatal diagnosis, operative management and outcome of esophageal atresia/ tracheoesophageal fistula. Prenat Diagn 2008;28:667-675.

44. Livera LN, Brookfield DSK, Egginton JA, Hawnaur JM. Antenatal ultrasonography to detect fetal renal abnormalities: a prospective screening programme. BMJ 1989;298:1421-1423.

45. Gunn TR, Mora JD, Pease T. Antenatal diagnosis of urinary tract abnormalities by ultrasonography after 28 weeks gestation: incidence and outcome. Am J Obstet Gynecol 1995; 172:479-486.

46. Romero R, Pilu G, Jeanty P. Prenatal diagnosis of congenital anomalies. Norwalk: Appleton \& Lange 1988:311-384.

47. Kennon JC, Vitsky JL, Tiller GE, Jeanty P. Osteogenesis imperfecta. Fetus 1994;4:11-14.

48. Altman RP, Randolph JG, Lilley JR. Sacrococcygeal teratoma: American Academy of Pediatrics Surgical Section Survey. J Pediatr Surg 1974;9:389-398.

49. Donnellan WA, Swenson O. Benign and malignant sacrococcygeal teratoma Surgery 1968;64:834.

50. Nyberg DA, McGahan JP, Pretorius DH, Pilu G. Diagnostic imaging of fetal anomalies. Lippincott Williams \& Wilkins 2003;7:325-326.

51. Nyberg DA, McGahan JP, Pretorius DH, Pilu G. Diagnostic imaging of fetal anomalies. Lippincott Williams \& Wilkins. 2003;6:278.

52. Nyberg DA, McGahan JP, Pretorius DH, Pilu G. Diagnostic imaging of fetal anomalies. Lippincott Williams \& Wilkins. 2003;6:279.

53. Mutchinick OM, Luna-Munoz L, Amar E, et al. Conjoined twins: a worldwide collaborative epidemiological study of the International clearing house for birth defects surveillance and research. Am J Med Genet C Semin Med Genet 2011;157C:274.

54. Van Den Brand SFJJ, Nijhuis JG, Van Dongen PWJ. Prenatal ultrasound diagnosis of conjoined twins. Obstet Gynecol Surv 1994;49:656.

55. Maymon R, Halperin R, Weinraub Z, et al. Three-dimensional transvaginal sonography of conjoined twins at 10 weeks: a case report. Ultrasound Obstet Gynecol 1998;11:292.

56. Usta IM, Awwad JT. A false positive diagnosis of conjoined twins in a triplet pregnancy: pitfalls of first trimester ultrasonographic prenatal diagnosis. Prenat Diagn 2000;20:169. 